UNIVERSIDADE DE SÃO PAULO

ESCOLA DE ENGENHARIA DE SÃO CARLOS

INSTITUTO DE FÍSICA DE SÃO CARLOS

INSTITUTO DE QUÍMICA DE SÃO CARLOS

\title{
DETERMINAÇÃO DO COEFICIENTE PIROELÉTRICO \\ DE POLÍMEROS UTILIZANDO A TÉCNICA DE \\ TEMPERATURA OSCILANTE NO TEMPO
}

\section{MANOEL GREGÓRIO DE MIRANDA FILHO}

Orientador: Prof. Dr. José Alberto Giacometti

Dissertação apresentada à Área Interunidades Ciência e Engenharia de Materiais da EESC, do IFSC e do IQSC e para a obtenção do título de Mestre em Ciência e Engenharia de Materiais.

USP/FSCISBI

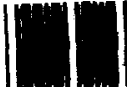

8-2-001316

São Carlos - SP

Novembro/1999 
MEMBROS DA COMISSÃO JULGADORA DA DISSERTAÇÃO DE MESTRADO DE MANOEL GREGORIO DE MIRANDA FILHO, APRESENTADA A ÁREA INTERUNIDADES EM CIÊNCIA E ENGENHARIA DE MATERIAIS, DA EESC-IFSCIQSC, UNIVERSIDADE DE SÃO PAULO, EM 12/11/1999.

COMISSÃO JULGADORA:
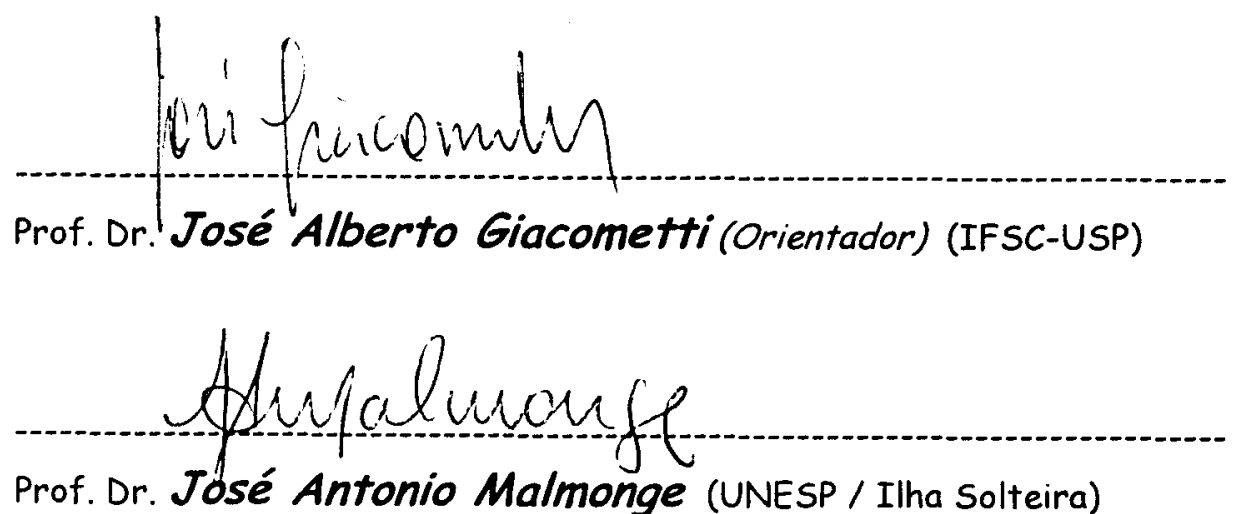

Prof. Dr. José Antonio Malmonge (UNESP / Ilha Solteira)

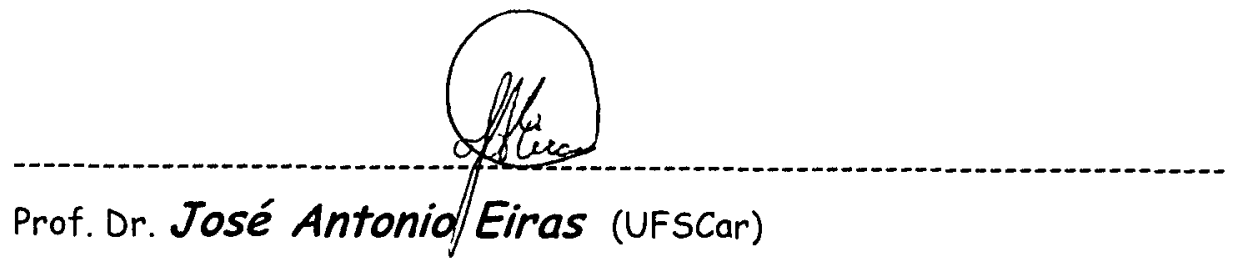




\section{Miranda Filho, Manoel Gregório de}

Determinação do Coeficiente Piroelétrico de Polímeros utilizando a técnica de temperatura oscilante no tempo/Manoel Gregório de Miranda Filho - São Carlos, 1999.

63p

Dissertação (Mestrado) -

Instituto de Física de São Carlos, 1999.

Orientador: Prof. Dr. José Alberto Giacometti

1.Ferroeletricidade.2.Piroeletricidade.3.Polarização elétrica.

I.Título 


\section{AgRadecimento}

A todas as pessoas que compartilharam direta ou indiretamente para a concretização deste trabalho. Cabe nesse momento os devidos agradecimentos como reconhecimento de suas valiosas colaborações e amizade durante esses anos. Em especial, agradeço:

Ao professor Giacometti, pela impecável orientação e pelo constante incentivo, que contribui muito para meu aprendizado nestes anos de mestrado; pela dedicação, paciência, amizade e presteza em indicar os caminhos para atingir as metas necessárias à conclusão do presente trabalho;

Aos alunos de doutorado Célio Wisniewski, pelo desenvolvimento dos programas de computador para aquisição de dados, Mauro e Walterley que comigo compartilharam seus trabalhos e dirimiram minhas dúvidas e, além disso, pela nossa sincera amizade;

Aos técnicos do "Grupo de Polímeros Bernhard Gross" do IFSC-USP, pela intensa colaboração na montagem experimental e apoio técnico na confecção de peças e execução de seus serviços com competência e dedicação: Rosângela, Ademir, Níbio e Bertho;

Ao professores Dr. Sérgio Roberto de Paulo e Ms. Denilton Carlos Gaio do Dept $^{0}$. de Física - UFMT, pelo curso nivelamento, assim como pela coordenação do acordo UFMT/USP;

Aos Colegas de trabalho da Secretaria do Estado de Educação do Estado de Mato Grosso (Centro de Estudo Supletivo), pela compreensão e amizade;

A Direção da Universidade de Cuiabá e aos professores da Coordenação de Biologia e Físico-Química, Departamento de Educação, por entender que a capacitação é extremamente importante para nossa instituição; Carlos;

Ao apoio prestado pelas Oficinas Mecânica e Eletrônica do IFSC - São

A minha esposa Uilza, e meus filhos Everton, Evelly e Eberty, pela paciência, compreensão e fundamental apoio, principalmente nas horas mais difíceis;

A todos os meus amigos "cuiabanos" que estiveram comigo nessa jornada;

A todos os colegas e professores do "Grupo de Polímeros" pela convivência durante a minha permanência aqui em São Carlos;

À todos aqueles que não foram lembrados, mais que, de uma forma ou de outra, contribuíram para realização deste trabalho;

Ao apoio financeiro do CNPq (bolsa), FAPESP, FINEP e CAPES. 


\section{DEDICAÇÃo ESPECIAL}

A minha querida mãe Alcina, agradeço o carinho, incentivo e esforço que me proporcionou o acesso a universidade.

Homenagem Póstuma

Ao meu querido pai Manoel Gregório e a minha inesquecível sogra Maria Avelina Botelho, pelo apoio e exemplo de vida durante as suas permanências entre nós. 


\section{SUMÁRIO}

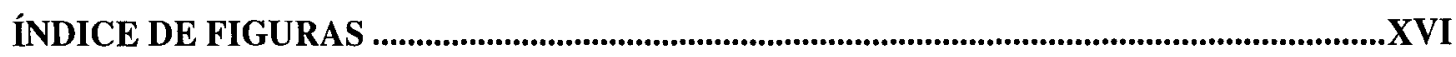

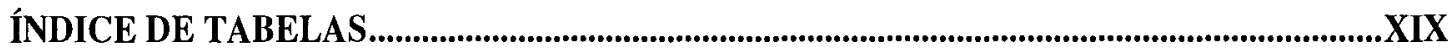

LISTA DE SÍMBOLOS ....................................................................................................... XX

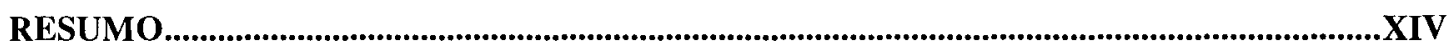

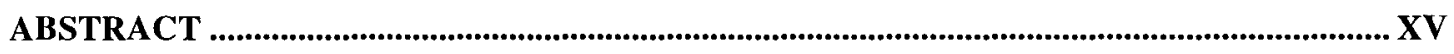

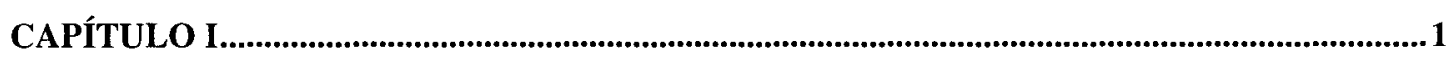

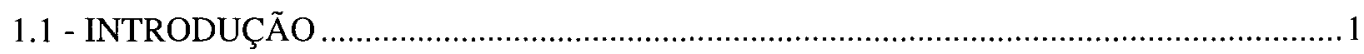

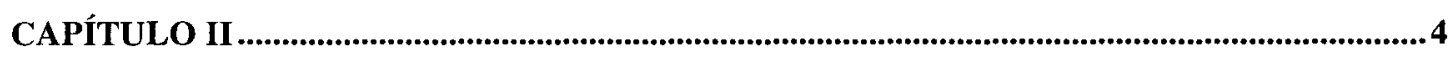

POLÍMEROS E MATERIAIS PIROELÉTRICOS ......................................................................4

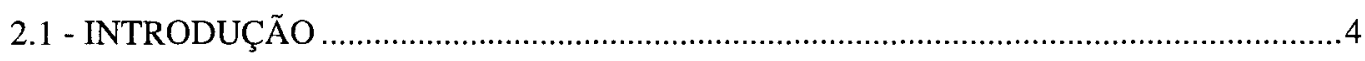

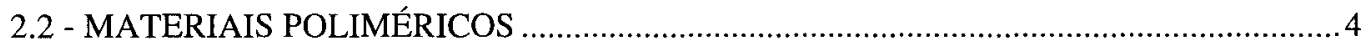

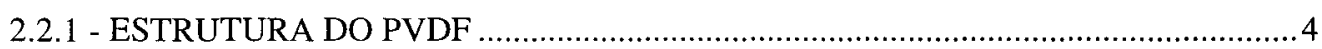

2.2.2 - POLI(METACRILATO DE METILA) …………............................................

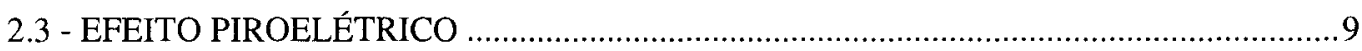

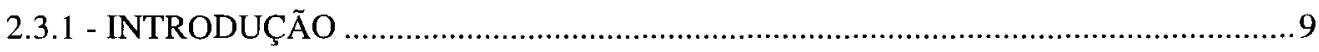

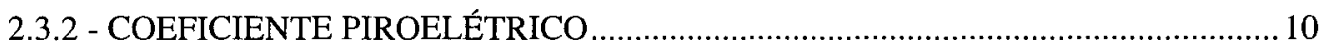

2.3.3 - PROPRIEDADES PIROELÉTRICAS DO PVDF E DO PMMA+DR1 .....................11

2.4 - MODELOS DO COEFICIENTE PIROELÉTRICO DO PVDF .......................................... 12

2.4.1 - MODELO DE BROADHURST E OUTROS ………............................................. 12

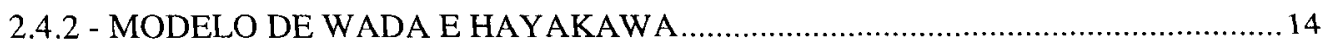




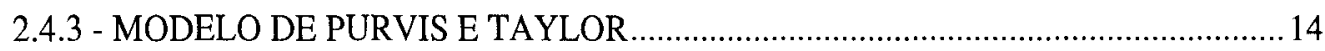

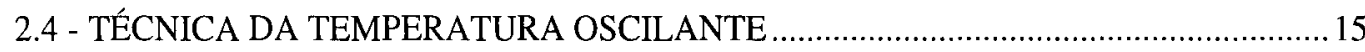

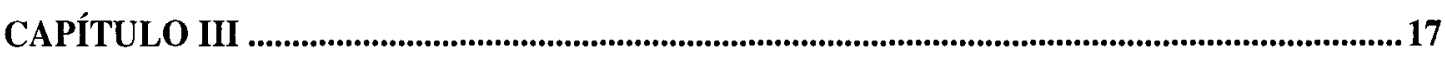

SISTEMA EXPERIMENTAL E AMOSTRAS...........................................................................17

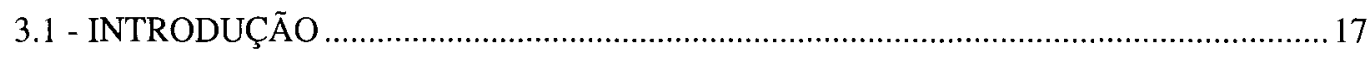

3.2 - DESCRIÇÃO DO SISTEMA DE MEDIDA ………………............................................. 18

3.2.1 - CIRCUITO ELÉTRICO E OS COMPONENTES ....................................................... 19

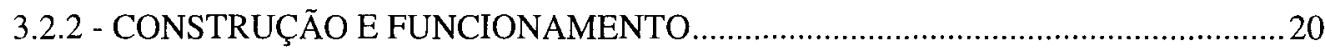

3.3 - PROCEDIMENTO PARA MEDIDAS DAS GRANDEZAS ……....................................22

3.3.1 - MEDIDA DA TEMPERATURA

3.4 - CONTROLE, AQUISIÇÃO DE DADOS E PROCESSAMENTO DE SINAIS..................23

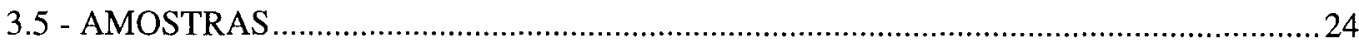

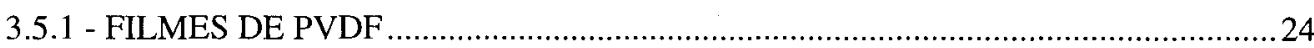

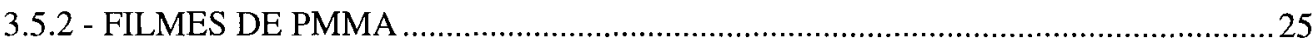

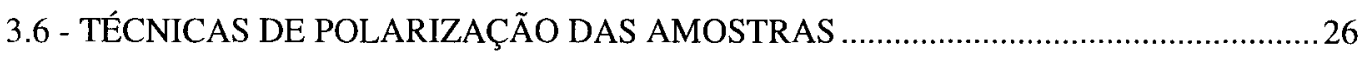

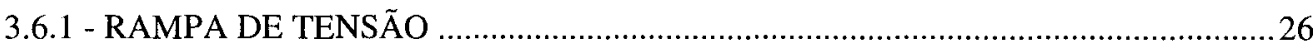

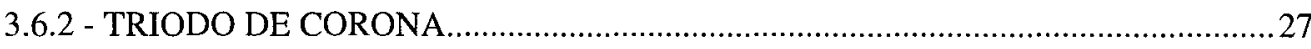

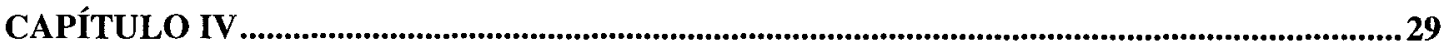

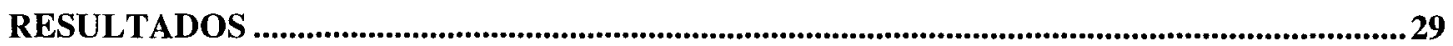

4.1 - INTRODUÇÃO

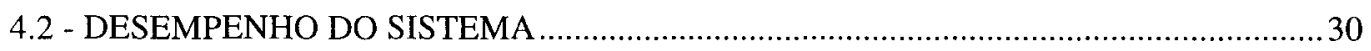

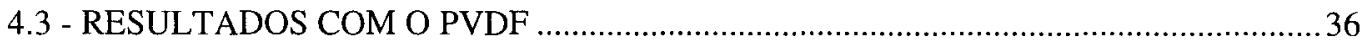

4.3.1 - COEFICIENTE PIROELÉTRICO VERSUS TEMPERATURA MÉDIA. ..................37

4.3.2 - COEFICIENTE PIROELÉTRICO VERSUS CAMPO ELÉTRICO DE

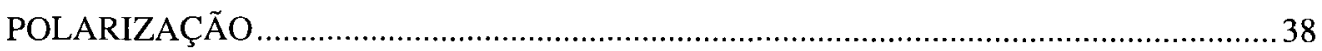

4.3.3 - COMPARAÇÃO DO COEFICIENTE PIROELÉTRICO COM A POLARIZAÇÃO

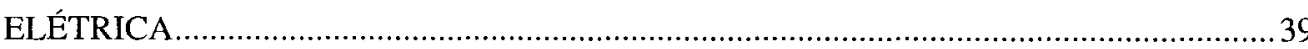

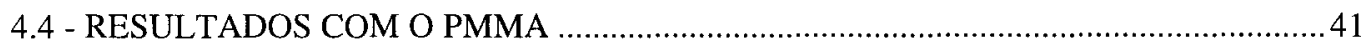


4.4.1 - COEFICIENTE PIROELÉTRICO EM FUNÇÃO DO CAMPO ELÉTRICO . .42

4.4.2 - COEFICIENTE PIROELÉTRICO EM FUNÇÃO DA CONCENTRAÇÃO DE CORANTE.

CAPítulO V . .45

COMENTÁRIOS E CONCLUSÕES. . .45

REFERÊNCIAS BILIOGRÁFICAS .47 


\section{ÍNDICE DE FIGURAS}

Figura 1 - Diagrama da estrutura de um polímero na forma semi cristalina. .5

Figura 2 - (a) Estrutura cristalina do PVDF fase $\alpha$; (b) projeção da rede na conformação $\mathrm{TG}+\mathrm{TG}^{-}$

Figura 3 - (a) Estrutura cristalina do PVDF fase $\beta$;(b) cadeia na conformação zig-zag planar.

Figura 4 - Diagrama da orientação molecular: (a) fase $\gamma$ e (b) fase $\delta$ .8

Figura 5 - Diagrama do monômero do PMMA. 8

Figura 6 - Molécula orgânica Vermelho Disperso 1 (DR1) .9

Figura 7 - Identificação dos eixos para o estiramento do polímero PVDF polarizado.

Figura 8 - Vista frontal de uma Célula Peltier. .18

Figura 9 - Desenho esquemático do sistema de medidas.

Figura 10 - Esquema elétrico simplificado para a medida da corrente e geração da temperatura senoidal.

Figura 11 - Desenho simplificado da montagem das células de Peltier. As áreas em amarelo representam os eletrodos.

Figura 12 - Vista lateral do sistema de medidas. 
Figura 15 - Diagrama esquemático do circuito de rampa de tensão .26

Figura 16 - Diagrama esquemático do triodo corona com corrente constante. $P$ é a ponta corona, $G$ é o anel de guarda, $E$ é o eletrômetro que mede a corrente, $V_{c}$ é a fonte de alta tensão que produz a descarga corona em $P$ e, $V_{g}$ é a fonte de tensão (operando no modo corrente constante) que polariza a grade. .28

Figura 17 - Temperatura e corrente versus tempo para a temperatura média de $18,90 \mathrm{C}$ e frequiência de $4 \mathrm{mHz}$. Amostra de PVDF $12 \mu \mathrm{m}$. .30

Figura 18 - Diagrama para a convenção do sinal do coeficiente piroelétrico A é eletrômetro $\mathrm{x}$ é a coordenada, $\mathrm{P}$ e $\Delta \mathrm{P}$ são a polarização e sua variação. ..33

Figura 19 - Coeficiente Piroelétrico versus freqüência de oscilação da temperatura para um campo de polarização de $250 \mathrm{MV} / \mathrm{m}$.

Figura 20 - Coeficiente Piroelétrico versus Amplitude de Temperatura com campo de polarização de 250MV/m .35

Figura 21 - Medidas da corrente piroelétrica versus a temperatura para freqüências de $2 ; 3$ e $4 \mathrm{mHz}$. .36

Figura 22 - Coeficiente Piroelétrico versus Temperatura, Frequiências entre 2; 3 e $4 \mathrm{mHz}$

Figura 23 - Coeficiente piroelétrico após 2 e 26 dias após o processo de polarização com campo de $250 \mathrm{MV} / \mathrm{m}$ aplicado na amostra. Frequiência de $4 \mathrm{mHz}$....38

Figura 24 - Coeficiente Piroelétrico versus campo elétrico, $f=10 \mathrm{mHz}$. 39

Figura 25 - Curva da polarização elétrica versus campo (linha cheia) e coeficiente piroelétrico versus campo de polarização. As escalas foram ajustadas para comparação das curvas.

Figura 26 - Dependência do coeficiente piroelétrico com o campo elétrico máximo. 
Figura 27 - Dependência do coeficiente piroelétrico com a concentração de DR1....44 


\section{ÍNDICE DE TABELAS}

Tabela 1 - Valores de $\Delta \mathrm{tm}, \Delta \mathrm{T}, \Delta \mathrm{I}, \mathrm{Tm}, \mathrm{e} \phi_{\mathrm{m}}$ para as curvas da Figura 17 31

Tabela 2 - Valores experimentais obtidos pelos dois Métodos de cálculo (M1-método

1 e M2-método 2). Temperatura média $48,2^{\circ} \mathrm{C}$. 


\title{
LISTA DE SÍMBOLOS
}

\author{
P Polarização elétrica \\ D Deslocamento elétrico \\ E Campo elétrico \\ A Área da amostra \\ I Corrente elétrica total \\ $\mathrm{I}_{\mathrm{p}} \quad$ Corrente piroelétrica \\ t Tempo \\ f Freqüência \\ Q Carga elétrica total \\ T Temperatura \\ C Capacitância \\ $\varepsilon_{\infty} \quad$ Permissividade elétrica a alta frequiência \\ $\varepsilon_{0} \quad$ Permissividade elétrica do vácuo \\ $\varepsilon_{\mathcal{c}} \quad$ Permissividade elétrica do cristal \\ $\varepsilon_{\mathrm{a}} \quad$ Permissividade elétrica do material amorfo \\ $\mathrm{P}_{\mathrm{sc}} \quad$ Polarização espontânea \\ $\mathrm{J}_{0}\left(\phi_{0}\right) \quad$ Função de Bessel \\ $\gamma \quad$ Constante de Gruneissen \\ $\alpha_{c} \quad$ Coeficiente de Expansão Térmica do Cristal \\ $\alpha_{s} \quad$ Coeficiente de Expansão Térmica da Amostra \\ $\phi_{c} \quad$ Fase Calculada \\ $\phi_{\mathrm{e}} \quad$ Fase Experimental \\ $J_{I}(t) \quad$ Densidade de Corrente com chaveamento \\ $\mathrm{J}_{2}(\mathrm{t}) \quad$ Densidade de Corrente sem chaveamento \\ $\mathrm{N} \quad$ Número de dipolos
}




\section{RESUMO}

O objetivo deste trabalho foi implementar um sistema para a determinação do coeficiente piroelétrico em materiais poliméricos. O método consiste em variar a temperatura da amostra de forma senoidal e medir a corrente em função do tempo. Através do sinal da corrente elétrica e da sua diferença de fase com a temperatura, separa-se a corrente elétrica de origem piroelétrica, a partir da qual se determina o coeficiente piroelétrico. Apresenta-se a caracterização do sistema abrangendo aspectos como o intervalo de temperatura das medidas e amplitude e freqüência da oscilação da temperatura. O método foi empregado para realizar medidas exploratórias com o polímero ferroelétrico poli(fluoreto de vinilideno), PVDF, polarizado pela aplicação de uma rampa de tensão, e com o polímero poli(metacrilato de metila), PMMA, com corante polar, polarizado com o triodo de corona. Nas medidas foram variados os parâmetros do processo de polarização elétrica tais como o campo elétrico máximo e a temperatura. 


\section{ABSTRACT}

An experimental setup to measure the pyroelectric coefficient of polymers was implemented. The method is based on the measurement of the electric current generated by the sample when its temperature was set to oscillate sinusoidally. Using the measured current and its phase difference related with the temperature the pyroelectric current was obtained, from that the pyroelectric coefficient was determined. It is shown the characterization of the experimental system such as the temperature amplitude and frequency interval of operation. The method was applied in exploratory measurements employing the ferroelectric polymer poly(vynilidene fluoride), PVDF, poled by a ramp voltage, and the poly(methyl metacrylate), PMMA, having a polar dye, poled with the corona triode. Measurements were performed for different poling conditions such as the maximum applied field and temperature. 


\section{CAPÍTULO I}

\section{1 - Introdução}

Desde que Kawai [1] descobriu a atividade piezoelétrica do poli(fluoreto de vinilideno) (PVDF), após submeter os filmes ao estiramento mecânico e subseqüentemente aplicação de campo elétrico, surgiu grande interesse pelas propriedades elétricas de polímeros. Dois anos mais tarde, Bergman [2] e colaboradores e Nakamura e Wada [3], descobriram a atividade piroelétrica e as propriedades ópticas não lineares no PVDF.

Polímeros ferroelétricos [4] como o PVDF e seus copolímeros P(VDFTrFE) e P(VDF-TeFE) são atualmente usados em diferentes aplicações tecnológicas [5] principalmente transdutores piezoelétricos e piroelétricos. Os compósitos de polímeros com cerâmicas ferroelétricas são também muito estudados, pois nesses materiais a resistência mecânica, flexibilidade e a baixa constante dielétrica dos polímeros podem combinar com o alto coeficiente piroelétrico das cerâmicas.

Os polímeros com propriedades ópticas não lineares têm despertado um interesse muito grande nos últimos anos, tanto do ponto de vista experimental, como teórico e tecnológico. Os polímeros possuem uma grande potencialidade nas aplicações em dispositivos para fotônica, tais como moduladores e chaves ópticas. Uma característica essencial para um sistema polimérico possuir atividade óptica não linear de segunda ordem é não possuir centro de simetria, isso significa que o 
material precisa ter dipolos alinhados. A condição da ausência de centro de simetria na estrutura polimérica é obtida por meio da polarização sob campo elétrico, que leva ao alinhamento nas moléculas não lineares, que dará origem a uma polarização elétrica no material.

A medida da atividade piroelétrica é um dos métodos pelo qual se pode caracterizar os materiais ferroelétricos e polares. Ela fornece informações sobre os fenômenos físicos da polarização elétrica e também permite avaliar a aplicabilidade do material em dispositivos piroelétricos [6]. O método mais comum para medida do coeficiente piroelétrico é o quase-estático. Nesse método a temperatura da amostra é aumentada a uma taxa constante enquanto se registra a corrente elétrica. A partir da corrente determina-se o coeficiente piroelétrico da amostra. Em materiais poliméricos a corrente medida é devido a duas contribuições: uma em fase e outra fora de fase com a variação de temperatura. No método acima elas não podem ser distinguidas.

O método de medida utilizado neste trabalho é baseado na oscilação senoidal da temperatura no tempo [7, 8]. Esse método permite separar a corrente elétrica em fase e a fora de fase com a temperatura, a partir das quais pode-se determinar o coeficiente piroelétrico do material polimérico. Uma tensão elétrica de baixa frequiência (na faixa de milihertz) é aplicada nas células de Peltier (entre as quais é colocada a amostra) fazendo a temperatura da amostra oscilar na forma desejada.

Esta dissertação está apresentada em 5 (cinco) capítulos como segue:

No Capítulo II, será feita uma breve descrição sobre os materiais poliméricos poli(metacrilato de metila)(PMMA) com corante polar e PVDF, suas principais aplicações, suas propriedades, os modelos teóricos para a determinação do 
coeficiente piroelétrico e o princípio de operação do método. No Capítulo III será descrita a montagem experimental, a operação do sistema, o controle da temperatura e descrição das amostras poliméricas utilizadas. No capítulo IV, apresentam-se os resultados experimentais de caracterização do sistema construído e os resultados obtidos com os polímeros PVDF e PMMA. No Capítulo V, apresenta-se as conclusões do trabalho e sugestões para trabalhos futuros. 


\section{CAPÍtUluo II}

\section{POLÍMEROS E MATERIAIS PIROELÉTRICOS}

\section{1 - Introdução}

Neste capítulo descreve-se os polímeros usados no trabalho, o poli (fluoreto de vinilideno), PVDF, e o poli (metil metacrilato), PMMA, e as suas propriedades piroelétricas. No item 2.2 descreve-se de forma breve as fases cristalinas do PVDF, a estrutura e as características dos filmes do PMMA com o corante com propriedades ópticas não lineares. No item 2.3 destaca-se a definição do coeficiente piroelétrico e modelos usados para materiais poliméricos. No item 2.4 descreve-se o princípio experimental empregado para medida do coeficiente piroelétrico.

\section{2 - Materiais poliméricos}

\subsection{1 - Estrutura do PVDF}

O PVDF é um polímero orgânico, isolante, com aproximadamente 50\% de cristalinidade [9], cuja estrutura consiste de cadeias macromoleculares resultantes da repetição de unidades elementares chamadas de monômeros. A unidade monomérica tem um momento de dipolo de $7.10^{-30} \mathrm{Cm}$. As cadeias se agrupam 
formando lamelas cristalinas, intercaladas por uma conformação amorfa. Por sua vez, as lamelas podem fazer parte de um arranjo maior, constituída de várias ramificações formando as fibrilas. Em polímeros pode-se encontrar ainda uma outra macroestrutura formada pelo crescimento radial das fibrilas chamadas de esferulítas. A Figura 1 mostra a representação típica destas estruturas.

O polímero PVDF é formado por unidades repetitivas $\left(-\mathbf{C H}_{2}-\mathbf{C F}_{2}-\right)_{\mathbf{n}}$ possuindo 4 (quatro) fases estruturais cristalinas distintas conhecidas na literatura por fases $\alpha, \beta, \gamma$ e $\delta[9]$.

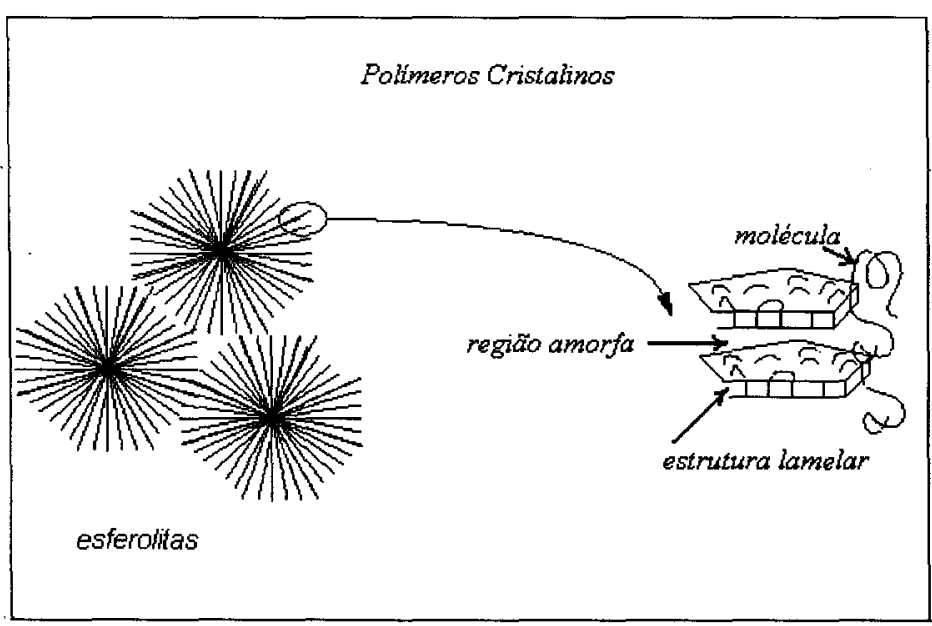

FIGURA 1 - Diagrama da estrutura de um polímero na forma semi cristalina.

A fase $\alpha$ é a estrutura mais comum do PVDF e é obtida por resfriamento a partir da fusão. As cadeias poliméricas na fase $\alpha$ possuem conformação $\mathrm{TG}^{+} \mathrm{TG}^{-} \mathrm{e}$ a cadeia apresenta uma ordem antipolar que produz momento de dipolo nulo no cristal, embora cada cadeia tem um momento de dipolo de $4.0 \times 10^{-30} \mathrm{Cm}$ e $3.4 \times 10^{-30} \mathrm{Cm}$ por monômero respectivamente perpendicular e paralelo à cadeia. A célula unitária da fase $\alpha$ do PVDF tem o grupo espacial de $\mathbf{P} \mathbf{2}_{\mathrm{cm}}$, é ortorrômbica e apresenta os parâmetros de rede $a=4.96 \AA, \quad b=9.64 \AA, c=4.62 \AA$, com 
$\alpha=\beta=\gamma=90^{\circ}$, sendo que c é o parâmetro ao longo do eixo da cadeia molecular, conforme mostrado na Figura 2.

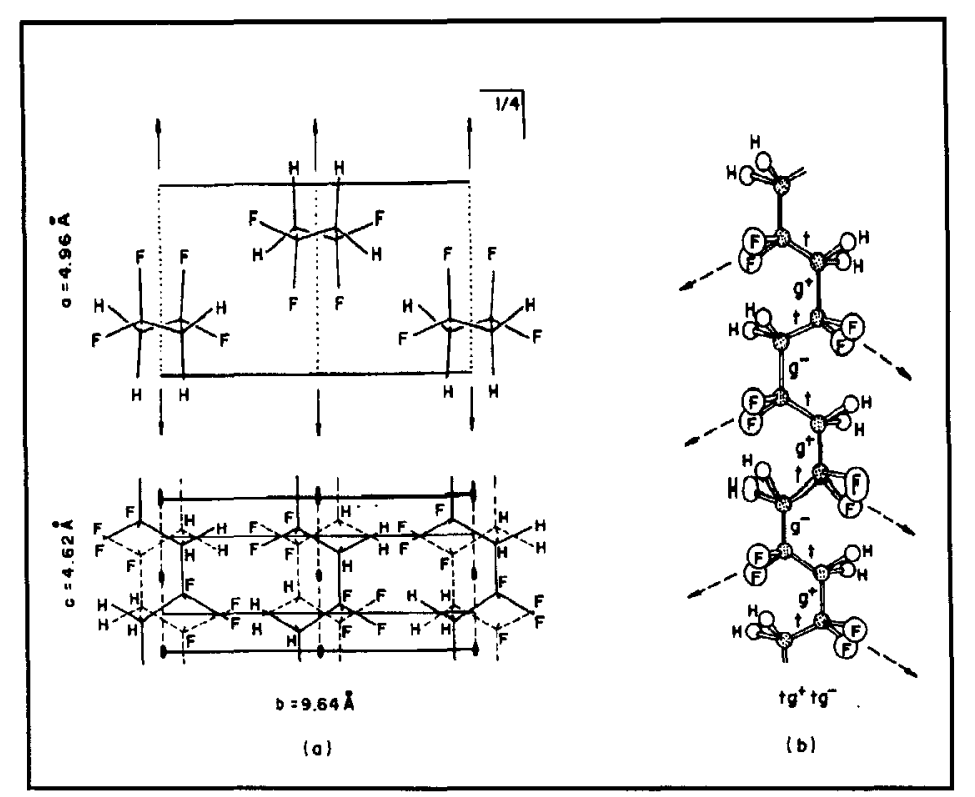

FIgURA 2 - (a) Estrutura cristalina do PVDF fase $\alpha$; (b) projeção da rede na conformação $\mathrm{TG}+\mathrm{TG}^{-}$.

A fase $\beta$ polar é considerada a mais importante do PVDF por apresentar maior atividade piezoelétrica [10] e piroelétrica [11 14]. Normalmente ela é obtida por estiramento mecânico de filmes na fase $\alpha$. A célula unitária da fase $\beta$ tem simetria ortorrômbica com grupo espacial $\mathrm{Cm} 2 \mathrm{~m}$ e a cadeia possui conformação zigzag. Apresenta como parâmetro de rede $a=8.58 \AA, b=4.91 \AA$ e $c=2.56 \AA$, conforme mostrado na Figura 3. O momento de dipolo da cadeia polimérica da fase $\beta$ é $7.0 \times 10^{-30} \mathrm{Cm}$ e é normal a direção da cadeia. 


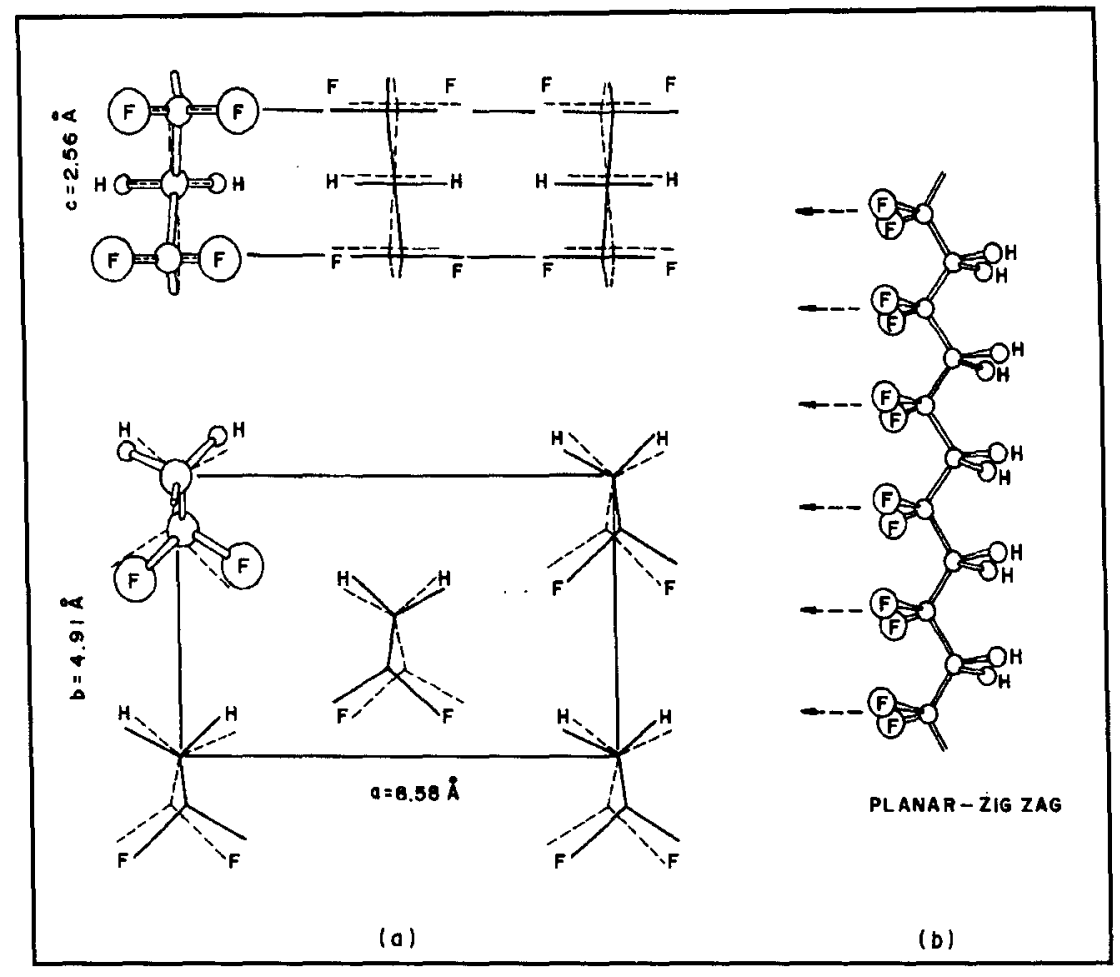

FIgURA 3 - (a) Estrutura cristalina do PVDF fase $\beta$;(b) cadeia na conformação zigzag planar.

A versão polar da fase $\alpha$ é conhecida como a fase $\delta$ ou fase $\alpha$-polar. Possui uma estrutura ortorrômbica P21Cn, com conformação das cadeias $\mathrm{TG}^{+} \mathrm{TG}^{-}$[9] com o vetor momento dipolo alinhado na mesma direção. Ocorre a mudança da fase $\delta$ para a fase $\beta$ quando se aplica um campo elétrico [15] menor que $400 \mathrm{MV} / \mathrm{m}$.

A outra fase do PVDF é a fase $\gamma$. A conformação da cadeia $\gamma$ é bem próxima à estrutura do tipo $\mathrm{T}_{3} \mathrm{GT}_{3} \mathrm{G}$ e é obtida em alta temperatura ou através do tratamento térmico da fase $\alpha$ em altas temperaturas, sendo que a taxa de transformação aumenta com as imperfeições dos cristais. Com base no processo de transformação da fase $\alpha$ para a fase $\gamma$ polar foi sugerido que a fase $\delta$ polar pode se transformar numa versão antipolar da fase $\delta$ contendo as cadeias $T_{3} G^{+} T_{3} G^{-}$que foi designada como fase $\varepsilon$. Ambas as estruturas possuem células unitárias polares, entretanto os momentos de dipolos são menores que aqueles da fase $\gamma$. 


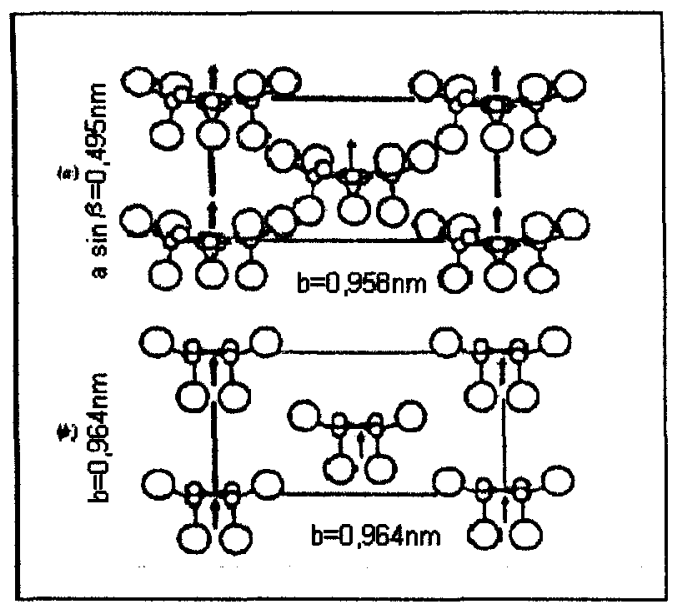

FIGURA 4 - Diagrama da orientação molecular: (a) fase $\gamma$ e (b) fase $\delta$.

\subsection{2 - Poli(metacrilato de metila)}

O poli(metacrilato de metila), PMMA, é um polímero que faz parte dos polímeros denominados acrílicos, é transparente e tem boa característica de resistência ao impacto. As principais características do PMMA são: incolor, transparente e resistente a impactos, amorfo, quebradiço e possui temperatura de transição vítrea em torno de $100^{\circ} \mathrm{C}$. O PMMA tem como monômero o metacrilato de metila e é sintetizado pelo processo de polimerização "radicalar" (através de radicais). A unidade monomérica do PMMA é mostrada na figura 5 e o PMMA é encontrado apenas na conformação atática e, portanto um polímero amorfo.

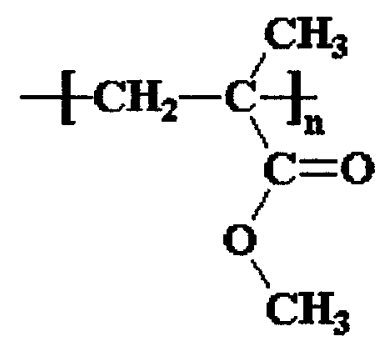

FIGURA 5 - Diagrama do monômero do PMMA. 
Sistemas poliméricos constituídos de polímeros misturados com corantes e possuindo um grupo cromóforo com propriedades ópticas não lineares tem sido bastantes investigados. Existem duas características fundamentais neste sistema polimérico: $1^{\circ}$ - baixa solubilidade dos corantes no polímero, no máximo $10 \% \mathrm{em}$ massa de corantes podem ser misturados aos polímeros sem que ocorra cristalização ou separação de fases. $2^{\circ}$ - baixa estabilidade da polarização, a qual pode decair em poucos dias, dependendo da temperatura.

Neste trabalho utilizou-se o poli(metacrilato de metila), PMMA, misturado ao corante vermelho disperso 1, DR1. Este corante é do tipo azobenzênico (4-(hidroxietil-etilamino)-4'-nitro-azobenzeno), cuja estrutura molecular é mostrada na Figura 6. A molécula DR1 tem estrutura molecular conjugada com terminação doadora e aceitadora de elétrons, com momento de dipolo da ordem de 10 Debyes. Quando misturado na matriz polimérica ele pode ser orientado por campo elétrico estático, em uma temperatura próxima a temperatura de transição vítrea do polímero.

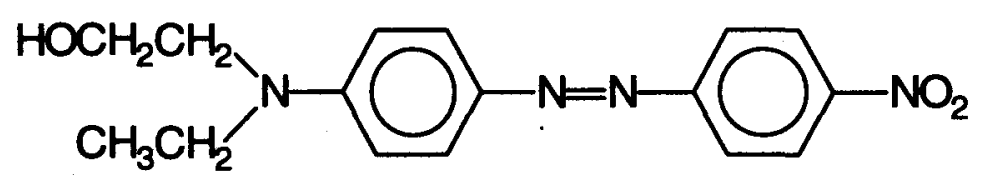

FiguRa 6 - Molécula orgânica Vermelho Disperso 1 (DR1)

\section{3 - Efeito Piroelétrico}

\subsection{1 - Introdução}

O efeito piroelétrico é um processo inerente à variação da polarização elétrica com a temperatura. Nos materiais ferroelétricos a direção de sua polarização pode ser revertida quando um campo elétrico é aplicado e a polarização desaparece 
acima da temperatura Curie, $\mathrm{T}_{\mathfrak{c}}$, por analogia ao ferromagnetismo. O efeito piroelétrico produzido durante o aquecimento do mineral turmalina era conhecido a centenas de anos pelo filósofo grego Theophrastus e levou a descoberta da piroeletricidade pelos irmãos Curie em 1880. As propriedades piroelétricas e piezoelétricas do sal de ROCHELLE foram estudadas por Valasek's e resultou na descoberta da ferroeletricidade em 1921. O polímero PVDF é ferroelétrico, exibindo propriedade piroelétrica enquanto que o PMMA+DR1 é não ferroelétrico, mas exibe propriedades piroelétricas devido à polarização elétrica do corante.

A importância do efeito piroelétrico na deteç̧ão do infravermelho se tornou óbvio, após Putley [16] publicar um artigo sobre detectores piroelétricos em 1970. Em 1971, Bergman, McFee e Crane [2] fizeram a primeira observação sobre a piroeletricidade em um filme de PVDF estirado e polarizado.

\subsection{2 - Coeficiente Piroelétrico}

O coeficiente piroelétrico, $p(T)$, depende da variação da polarização elétrica $[17,18]$ da amostra com a temperatura, é definido como:

$$
p=\left(\frac{d P}{d T}\right)_{(E, X)}
$$

onde $P$ é a polarização elétrica, $T$ é a temperatura, $E$ o campo elétrico e $X$ a tensão mecânica sobre a amostra (os índices indicam que esses parâmetros são mantidos constantes). O deslocamento elétrico, $D=\varepsilon E+P$, permite escrever para $E=0$ (eletrodos em curto circuito) que:

$$
p=\left(\frac{d P}{d T}\right)_{(E, X)}=\left(\frac{d D}{d T}\right)_{(E, X)}=\left(\frac{1}{A} \frac{d Q}{d T}\right)_{(E, X)}=\frac{I}{A} \frac{1}{d T / d t}
$$


onde $Q$ é carga elétrica, $A$ é a área do eletrodo e $I$ a corrente na amostra, $\frac{d T}{d t}$ é variação da temperatura no tempo.

\subsection{3 - Propriedades Piroelétricas do PVDF e do PMMA+DR1}

O tensor piroelétrico para o PVDF é dado por

$$
\left[\begin{array}{c}
0 \\
0 \\
-p_{3}
\end{array}\right]
$$

As convenções usuais para denominação dos eixos do filme são:

a) Eixo 1 - correspondente a direção de estiramento do filme;

b) Eixos 2 e 3 - correspondem às direções perpendiculares ao estiramento do filme.

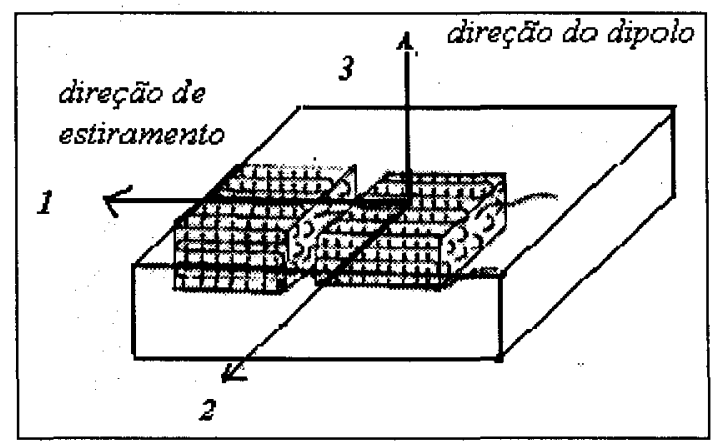

FIGURA 7 -Identificação dos eixos para o estiramento do polímero PVDF polarizado.

Como não existe momento de dipolo ao longo das direções 1 e 2 no filme do PVDF, conforme é mostrado na Figura $7, p_{1}=p_{2}=0$. Então, a piroeletricidade do PVDF ocorre somente na direção de $p_{3}$. Um aumento na temperatura do material aumentará seu volume, que resultará numa diminuição na polarização, de forma que $p_{3}$ é negativo. Isto significa que um aumento da temperatura [19] induz uma variação de polarização oposta na polarização remanescente $P_{0}$ do filme. 
O PMMA misturado com o corante polar DR1 também apresenta atividade piroelétrica após ser polarizado eletricamente. A diferença básica do PMMA+DR1 quando comparado com o PVDF é que a orientação da polarização é conseguida quando o material é polarizado a uma temperatura acima da temperatura ambiente e depois é resfriado. O PMMA apresenta atividade piroelétrica na direção perpendicular ao filme e também com valor negativo.

\section{4 - Modelos do coeficiente piroelétrico do PVDF}

Há vários modelos que podem ser utilizados para estimar o coeficiente piezelétrico e o piroelétrico $[20,21,17]$ nos polímeros ferroelétricos. Os modelos de Broadhurst e outros [20, 22, 23] Wada e Hayakawa [24] e Purvis e Taylor [21] receberam maior atenção.

\subsection{1 - Modelo de Broadhurst e outros}

Esse modelo é baseado na reorientação dos dipolos devido à mudança do volume devido às variações da pressão e temperatura do material. Com o alinhamento dos dipolos no cristal polar, a polarização resultante, $P_{0}$, é dada por.

$$
P_{0}=\left(\frac{\varepsilon_{\infty}+2}{3}\right) \frac{N}{V} \mu_{0}\langle\cos \varphi\rangle
$$

onde $N$ é o número de dipolos num cristal de volume $V, \varepsilon_{\infty}$ é a permissividade para alta freqüência, $\mu_{0}$ é o momento de dipolo no vácuo e $\langle\cos \varphi\rangle$ é o valor médio do cosseno do ângulo formado entre as direções dos dipolos e do campo de polarização. O modelo foi desenvolvido para polímeros amorfos, mas foi também aplicado [23] à polímeros semicristalinos como o PVDF, no qual os cristais são finas camadas com o 
vetor polarização perpendicular a superfície. Neste caso, o momento do dipolo no vácuo $\mu_{0}$ torna-se $\left(\varepsilon_{C}+2\right) \mu_{0} / 3$, onde $\varepsilon_{C}$ é a constante dielétrica do cristal devido à polarização de dipolos nos cristais, isto é, devido a interação com o campo elétrico dos dipolos vizinhos. Neste modelo o coeficiente piroelétrico $p$ é dado por

$$
p=-P_{0}\left[\alpha_{c}\left(\frac{\varepsilon_{c}-1}{3}\right)+\frac{\alpha_{c} \Phi_{0}^{2}}{2}\left[\gamma+\left(2 T \alpha_{c}\right)^{-1}+\frac{\alpha_{s}}{2}\right]\right]
$$

e $P_{0}$ dado por

$$
P_{0}=\Phi\left[\frac{\alpha_{c}+2}{3}\right] \frac{N \mu_{0}}{V_{c}} J_{0}\left(\Phi_{0}\right)\langle\cos \varphi\rangle
$$

onde $\Phi$ é fração do volume do cristal, $J_{0}\left(\Phi_{0}\right)$ representa a função de Bessel devida à oscilações harmônicas dos dipolos com amplitude média $\Phi_{0}, \gamma$ é a constante de Gruneissen que surge da variação da freqüência de oscilação em função do volume do cristal, $\alpha$ o coeficiente de expansão térmica e $T$ temperatura (os índices $c$ e $s$ referem-se respectivamente ao cristal e a amostra como um todo). Na equação (II.4) o valor de $P_{0}$ é o valor obtido experimentalmente através da polarização remanescente medida pelo método do ciclo de histerese ou outro método. O primeiro termo do parênteses na equação (II.5) corresponde à variação da constante dielétrica do cristal com a temperatura e constitui a contribuição eletrostática. O segundo termo surge da mudança da amplitude de oscilação que produz uma mudança na polarização e o terceiro termo é a contribuição da variação da espessura do polímero.

Broadhurst e outros, concluíram que há uma concordância entre a teoria e a prática e sendo a maior contribuição de $50 \%$ ao coeficiente piroelétrico devida a variação do volume, $23 \%$ da oscilação dos dipolos moleculares e $27 \%$ baseado no efeito de variação do campo local. O valor previsto para este método é de 
$20 \mu \mathrm{C} /{ }^{0} \mathrm{Cm}^{2}$ em bom acordo com o resultado experimental, da ordem de 20 a $30 \mu \mathrm{C} /{ }^{0} \mathrm{Cm}^{2}$.

\subsection{2 - Modelo de Wada e Hayakawa}

O modelo descrito por Wada e Hayakawa assume a existência de cristais esféricos polares com uma constante dielétrica $\varepsilon_{\mathfrak{c}}=3.3$ e localizados em um material amorfo de constante dielétrica média $\varepsilon_{\mathrm{a}}$. A polarização total $P_{\mathrm{s}}$ de um filme é dada por

$$
P_{s}=\phi\left(\frac{3 \varepsilon_{u}}{2 \varepsilon_{a}+\varepsilon_{c}}\right) P_{s c}
$$

onde $\Phi$ é a fração do volume polar e $P_{\mathrm{sc}}$ a polarização espontânea. Neste modelo não aparece a contribuição da amplitude de oscilação e a constante dielétrica tanto da amostra como do cristal deve ser considerada. As variações dimensionais tanto da amostra como do cristal contribuem respectivamente com $47 \%$ e $53 \%$. O coeficiente piroelétrico calculado é $-27 \mu \mathrm{C} /{ }^{0} \mathrm{Cm}^{2}$, também em bom acordo com o valor experimental obtido para o PVDF.

\subsection{3 - Modelo de Purvis e Taylor}

Purvis e Taylor mostraram que o valor de $P_{0}$ calculado na equação (II.3) é válida somente para os cristais nos quais os dipolos ocupam uma posição de simetria cúbica. No PVDF na fase $\beta$ os cristais têm uma estrutura ortorrômbica de base centrada. Eles admitiram que as propriedades mecânicas do filme de PVDF estirado e orientado (determinadas por OHIGASHI [25]), para temperaturas abaixo da temperatura de transição vítrea, eram propriedades do cristal. Foi assumido que a 
parte amorfa era responsável apenas para transmitir os esforços mecânicos e as mudanças nas dimensões com a temperatura. Eles encontraram que a contribuição devido à variação do campo é maior que a contribuição devida à variação nas dimensões. Apesar das limitações, o modelo também fornece boa concordância entre o coeficiente piroelétrico calculado e o medido experimentalmente para o PVDF na fase $\beta$.

\section{4 - Técnica da temperatura oscilante}

Como foi mencionado, neste trabalho usou-se o método de medida baseado na temperatura oscilante no tempo (senoidal), utilizado por Garn e Sharp e outros $[8,6]$. A amostra já polarizada eletricamente é colocada entre duas células de Peltier, nas quais a temperatura varia de forma senoidal e mede-se a corrente elétrica gerada pela amostra. Esta técnica permite a separação de corrente piroelétrica e não piroelétrica e faz uso do fato que a corrente piroelétrica é diretamente proporcional a derivada da temperatura no tempo, veja equação II-2. A corrente piroelétrica tem o angulo de fase igual a $\pi / 2$ radianos e a corrente não piroelétrica o ângulo de fase é igual a zero. O tempo de relaxação associado com a mudança da polarização é da ordem de microssegundos, um tempo muito menor que a constante térmica da amostra. Uma vez que o tempo de relaxação da polarização é pequeno comparado com o tempo de medida, a corrente produzida é proporcional à derivada da temperatura no tempo, resultando numa corrente reversível assim que inicia o aquecimento ou resfriamento e desaparecendo quando para o aquecimento ou resfriamento da amostra. No método senoidal de variação da temperatura pode ser escrita na forma 


$$
T(t)=\Delta T e^{j \omega t}
$$

e a corrente elétrica como

$$
I_{p}(t)=\Delta l e^{j(\omega t+\Phi)}
$$

onde $\Delta \mathrm{T}$ e $\Delta \mathrm{I}$ são respectivamente as amplitudes da temperatura e da corrente elétrica, $\Phi$ é o angulo de fase e $\omega$ é a frequiência angular. A corrente piroelétrica é escrita, eq. II.2, como:

$$
I_{p}=A p \frac{d T}{d t}
$$

usando as equações (II.7) e (II.8) tem-se

$$
\Delta l e^{j(\omega++\infty)}=A p \Delta T j \omega e^{j \omega x}
$$

ou seja:

$$
\Delta I(\cos \Phi+j \operatorname{sen} \Phi)=A p j \omega \Delta T
$$

e igualando as partes imaginárias de ambos os lados da equação tem-se a expressão para determinar o coeficiente piroelétrico

$$
p=\frac{\Delta I \operatorname{sen}(\Phi)}{\omega A \Delta T}
$$

onde $\mathbf{A}$ é a área do eletrodo da amostra. 


\section{CAPÍTULO III}

\section{SISTEMA EXPERIMENTAL E AMOSTRAS}

\section{1 - Introdução}

Neste capitulo descreve-se o sistema de medidas com detalhes de sua construção, equipamentos utilizados, circuitos utilizados, detalhes de operação e procedimento para a determinação do coeficiente piroelétrico. No final descreve-se as amostras e os métodos para polarizá-las.

Tendo em vista que células de Peltier são usadas para obter variações de temperaturas senoidais faz-se inicialmente uma breve descrição do seu funcionamento. A célula Peltier é um dispositivo eletro-térmico no qual uma de suas faces pode ser aquecida enquanto que a outra é resfriada. Isto é o resultado da passagem da corrente pelas junções de semicondutores montadas entre duas superfícies de cerâmicas conforme ilustrado na figura 8 . Na junção fria a energia (calor) é absorvida através dos movimentos dos elétrons quando eles passam de um nível mais baixo de energia do elemento semicondutor do tipo-p, para um nível mais alto de energia do elemento semicondutor do tipo-n. Na junção quente o processo é inverso, isto é, o movimento dos elétrons vai dos níveis mais altos de energia para o 
mais baixo nível de energia. O lado frio e o lado quente são determinados pela direção do fluxo da corrente. Os materiais termoelétricos são compostos de ligas quaternárias de bismuto, telúrio, selênio e antimônio, com pequenas quantidades de dopantes e as ligas cuidadosamente processadas para produzir uma orientação policristalina com propriedades termoelétricas anisotrópicas.

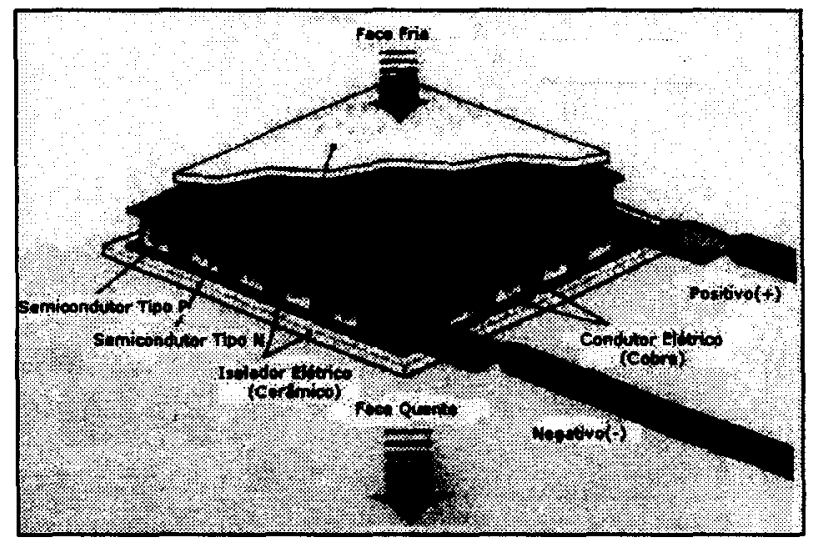

Figura 8 - Vista frontal de uma Célula Peltier.

\section{2 - Descrição do sistema de medida}

O desenho esquemático do sistema de medidas é mostrado na figura 9. Ele consiste das células Peltier, entre as quais a amostra e os eletrodos são colocados, voltímetro para a leitura da tensão elétrica dos termopares, eletrômetro, gerador de sinal de baixa frequiência e amplificador de potência, termopares e microcomputador para controle e aquisição de dados. 


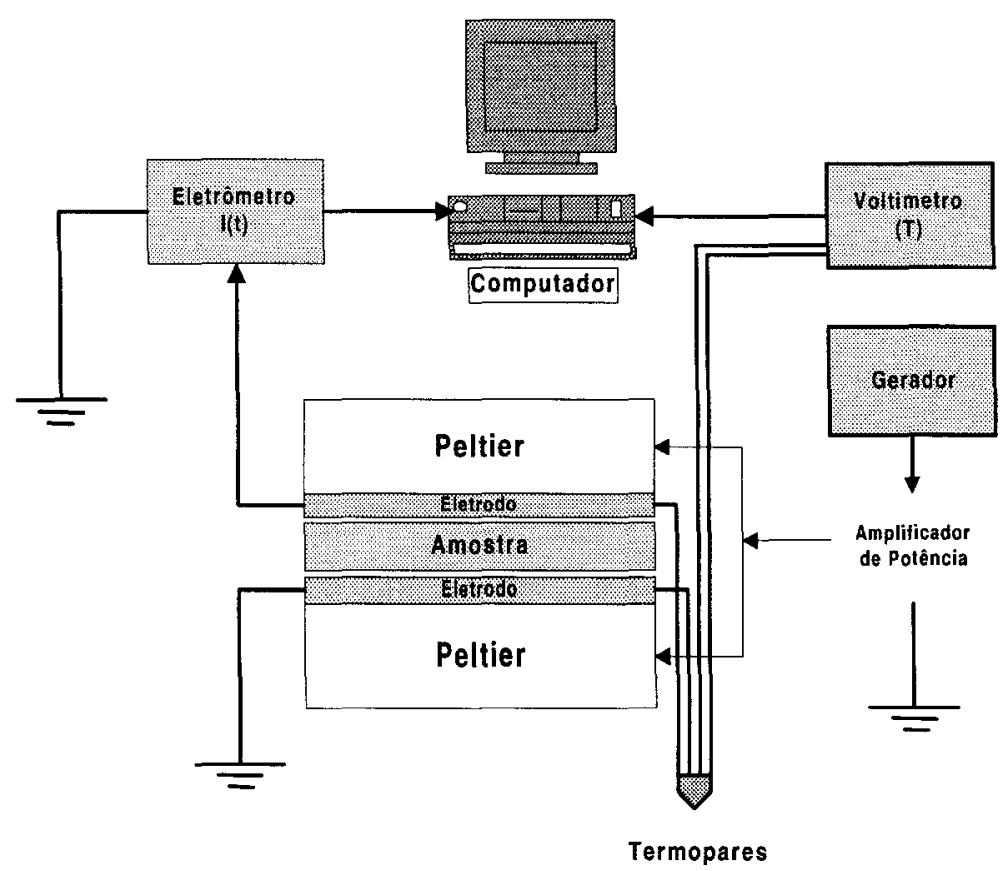

FIGURA 9 - Desenho esquemático do sistema de medidas.

A figura 10 mostra o esquema simplificado do sistema de amostra, eletrodos e células de Peltier com o objetivo de mostrar as grandezas físicas relevantes neste tipo de medida.

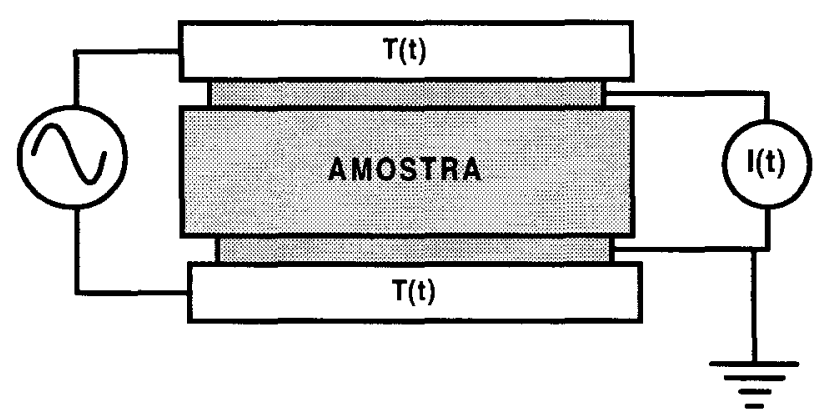

FigURA 10 - Esquema elétrico simplificado para a medida da corrente e geração da temperatura senoidal.

\subsection{1 - Circuito elétrico e os componentes}

Os equipamentos que constituem o sistema são:

Gerador de Sinal (Keithley-3940) - tem a função de gerar a tensão senoidal de baixa freqüência. 
Amplificador de Potência (Tectrol 20-03) - fonte de tensão programável e foi utilizada como amplificador de potência do sinal do gerador Keithley.

Célula de Peltier - elemento usado para variar a temperatura de forma senoidal. Utilizou-se células do tipo CP1.4-71-10L (Melcor Eletronics).

Eletrômetro (Keithey-610C) - é o equipamento de medida da corrente gerada pela amostra.

Multímetro Digital (Keithey-195A) - é o voltímetro de alta resolução $(0,1 \mu \mathrm{V})$ para a leitura da tensão elétrica de termopares. Ele possui interface do tipo GPIB.

Termopares (Omega Eng. Inc.) - dois termopares do tipo T (Cobre constatam) acoplados nos eletrodos .

Banho Termostático (Polystat ${ }^{\circledR}$ ) - através deste banho pode-se controlar a temperatura média na qual será realizada a medida. Ele é usado para circular a água a temperatura constante, no porta-amostra.

Computador - utilizamos um microcomputador PC "Pentium" e interfaces A/D e D/A para controle e aquisição de dados (Lab PC+ da National Instr. Inc) e interface GPIB (General Purpose Interface Bus).

\subsection{2 - Construção e funcionamento}

O porta amostra utilizado nas medidas é mostrado na Figura 11. Ele foi projetado pelos técnicos do Grupo de Polímeros "Prof. Bernhard Gross" e construído pela oficina mecânica da Física. O suporte foi confeccionado em latão com as dimensões de $60 \mathrm{~mm} \times 60 \mathrm{~mm} \times 10 \mathrm{~mm}$. O conjunto é constituído de dois blocos cúbicos ocos, para permitir a circulação de água. A parte inferior é fixada em uma 
base e a parte superior movimenta-se através de um guia, para facilitar o manuseio do sistema e centralizar os eletrodos.
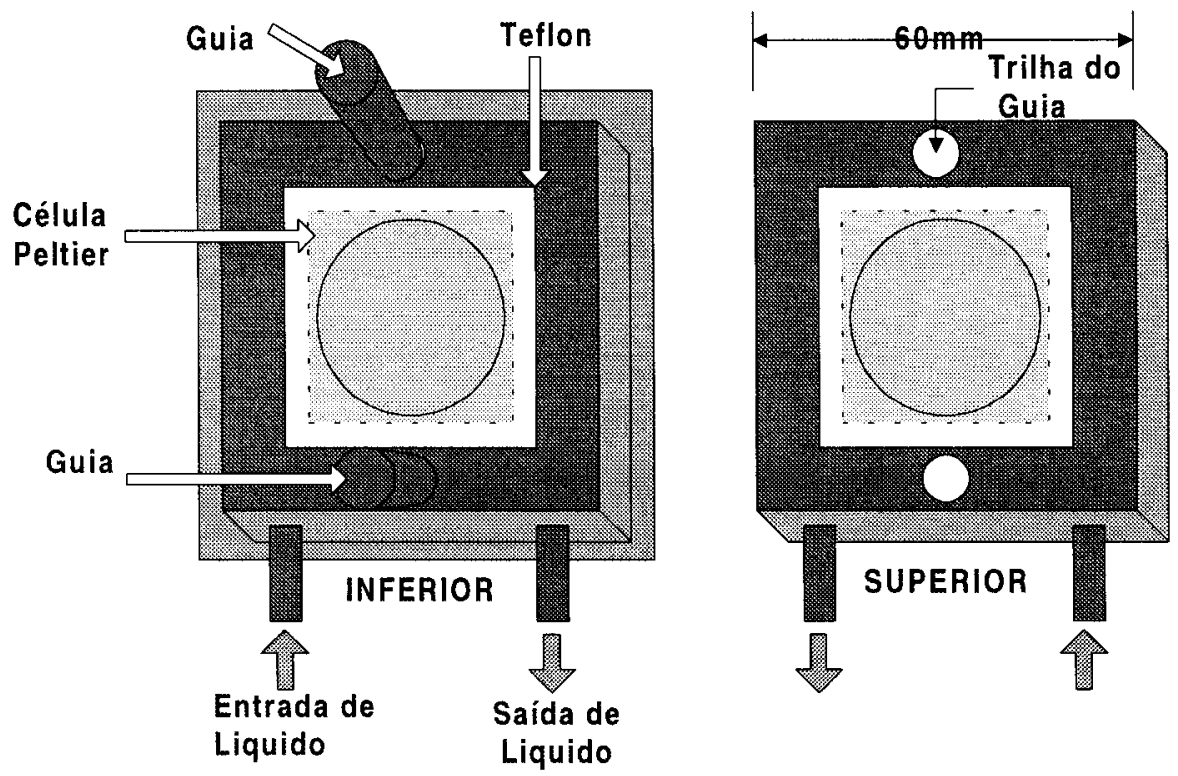

Figura 11 - Desenho simplificado da montagem das células de Peltier. As áreas em amarelo representam os eletrodos.

As células Peltier são fixadas sobre as duas bases metálicas cúbicas ocas através das quais circulam água, a temperatura constante. Entre as superfícies da célula Peltier e do eletrodo foi inserida uma camada de pasta térmica para garantir o bom contato térmico entre elas. Os eletrodos de cobre de $1,5 \mathrm{~mm}$ de espessura foram banhados com ouro para evitar oxidação, o eletrodo inferior é ligado ao eletrômetro e o superior é aterrado e o conjunto das células/eletrodos foi isolado eletricamente com Teflon. O sistema é colocado em uma caixa metálica blindada, e aterrada para evitar ruídos elétricos nas medidas e a caixa revestida internamente e externamente com isopor, como mostra a Figura 12. A caixa metálica é colocada dentro de uma caixa de isopor isolando-a termicamente do meio ambiente. 


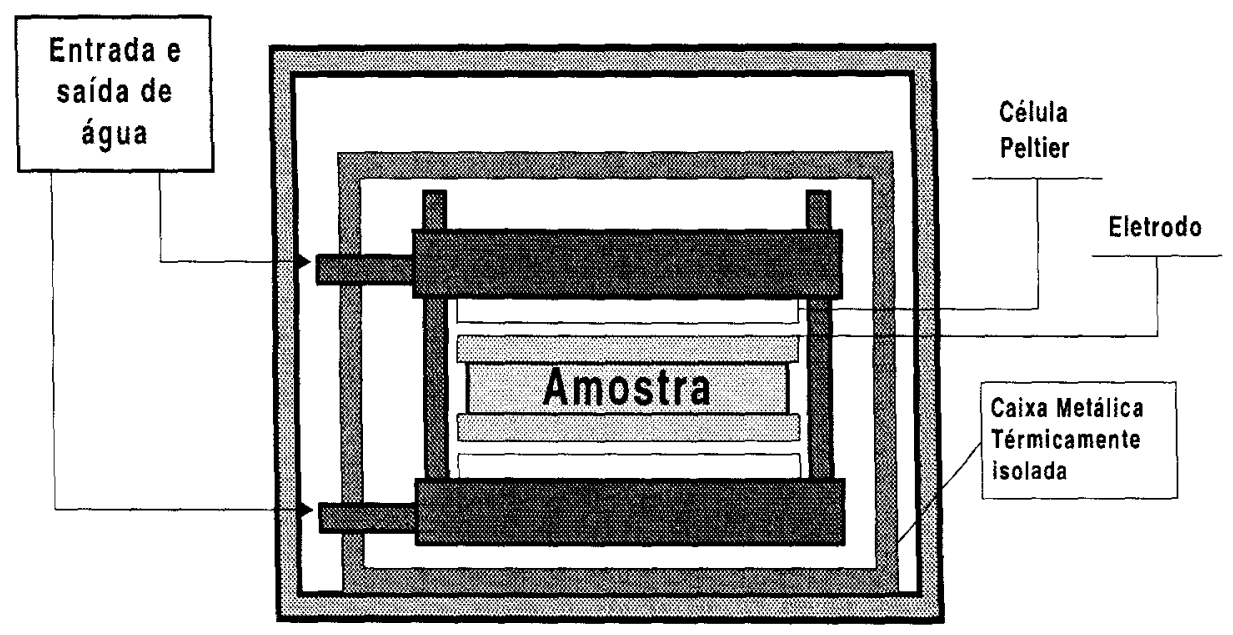

Figura 12 - Vista lateral do sistema de medidas.

\section{3 - Procedimento para medidas das grandezas}

\subsection{1 - Medida da temperatura}

Uma forma para se medir a temperatura é utilizar termopares. Eles caracterizam-se por apresentarem uma diferença de potencial entre seus terminais, que depende da temperatura na qual se encontra a junção do termopar. O princípio de funcionamento dos termopares é baseado no efeito Seebeck, onde a junção de dois metais ou ligas diferentes produz uma tensão elétrica proporcional à temperatura na qual se encontra. Por este mesmo princípio, quando se conecta as outras duas extremidades dos fios do termopar, forma-se outras junções de metais diferentes, que poderão alterar o valor medido. Para compensá-las é utilizada uma segunda junção de referência de modo que a junção criada pela conexão com o voltímetro seja do mesmo material, ou seja, a diferença de potencial gerada por uma seja cancelada por outra. Se a segunda junção, de referência ficar ao ar livre, detectará as variações de temperatura do meio ambiente acrescentando um erro na medida. Para evitar tal problema, é conveniente manter a junção de referência sob temperatura fixa de modo 
que a variação medida seja correspondente à variação da outra junção. Neste trabalho usa-se como referência à temperatura de $0^{\circ} \mathrm{C}$, obtida com um banho de gelo e água.

Para converter a tensão em temperatura, utilizamos os dados da tabela do termopar tipo $\mathrm{T}(\mathrm{Cu}-\mathrm{Co})$, fornecida pelo fabricante (Omega Engineering, Inc.). Foi traçada a curva de calibração leitura em milivolts versus temperatura em graus centígrados e após a inversão dos parâmetros, obtemos a seguinte equação:

$$
T\left({ }^{0} C\right)=\sqrt{25082,95 \times V(m V)+235332,56}-485,10
$$

Esta equação foi introduzida no programa de coletas de dados podendo-se obter diretamente o valor da temperatura em graus Celsius.

\section{4 - Controle, aquisição de dados e processamento de sinais.}

O programa de coleta de dados foi desenvolvido pelo aluno de doutorado Célio Wisniewski. A coleta é realizada por dois processos simultâneos de aquisição: a corrente piroelétrica e a temperatura. A corrente piroelétrica é medida através do eletrômetro que a converte em sinal de tensão, a qual é lida pelo conversor analógico digital conectado ao microcomputador. $O$ sinal da temperatura média, medida através de dois termopares, é transferido ao microcomputador PC através de uma interface tipo GPIB. A seqüência de medidas é determinada pelo microcomputador, onde a coleta dos dados (temperatura e corrente), é feita em tempo real e os dados obtidos armazenadosyno disco rígido. Com o auxilio do programa "Origin 5.0-Microcal Inc" obtém-se ơs gráficos da temperatura e corrente em função do tempo. A diferença de fase da corrente é determinada dos ciclos senoidais da temperatura e da corrente, conforme mostrado na figura 13. Os procedimentos detalhados para a determinação do coefíciente piroelétrico serão mostrados no Item 4.2. 


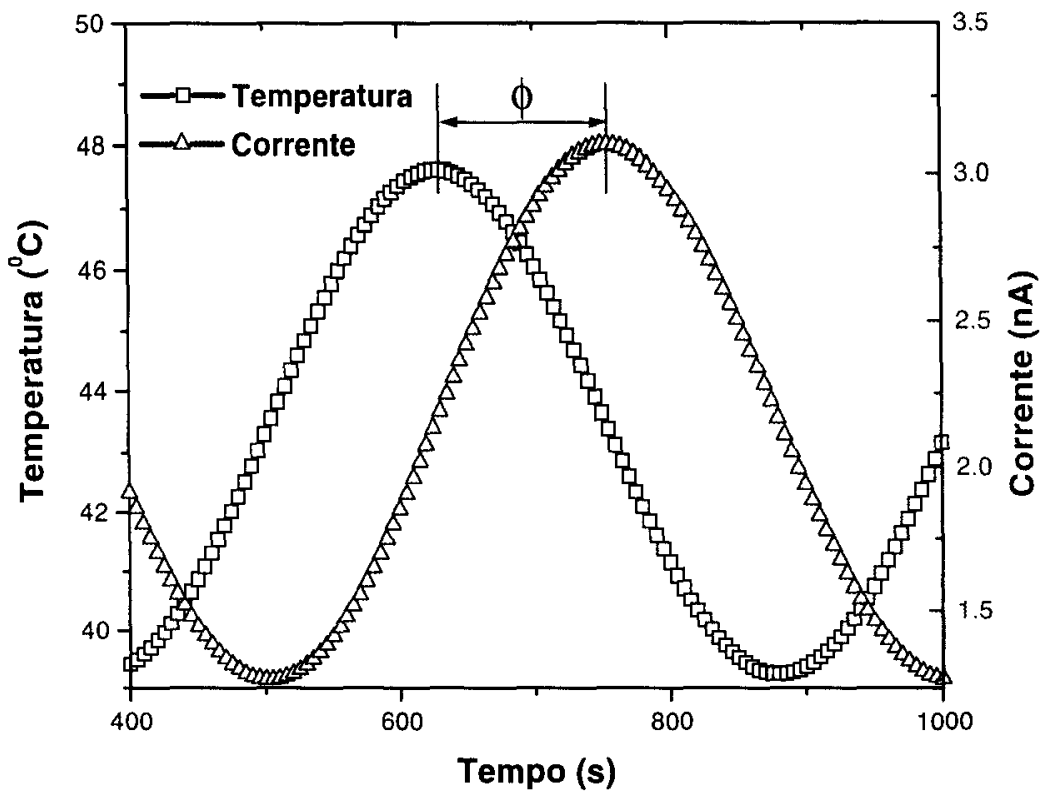

Figura 13 - Curva senoidal da Temperatura e Corrente versus Tempo.

\section{5 - Amostras}

\subsection{1 - Filmes de PVDF}

Estudou-se o poli(fluoreto de vinilideno), PVDF, fornecido pela Kureha Chemical Industry Company, de espessura $12 \mu \mathrm{m}$ e biaxialmente estirado. A cristalinidade do polímero é da ordem de $42 \%$ e a razão entre as fases $\beta$ e $\alpha$ existentes no material (como recebido do fabricante) é da ordem de $45 \%$. A amostra é fixada em um anel de PVC de $0,6 \mathrm{~mm}$ de espessura e $34 \mathrm{~mm}$ de diâmetro, conforme mostrado na figura 14. A amostra é limpa com álcool isopropílico; em seguida é metalizada com alumínio ( $200 \mathrm{~nm}$ de espessura) em ambas superfícies. A metalização foi realizada através de máscaras, utilizando evaporação em vácuo. A área metalizada é $5.73 \mathrm{~cm}^{2}$. 


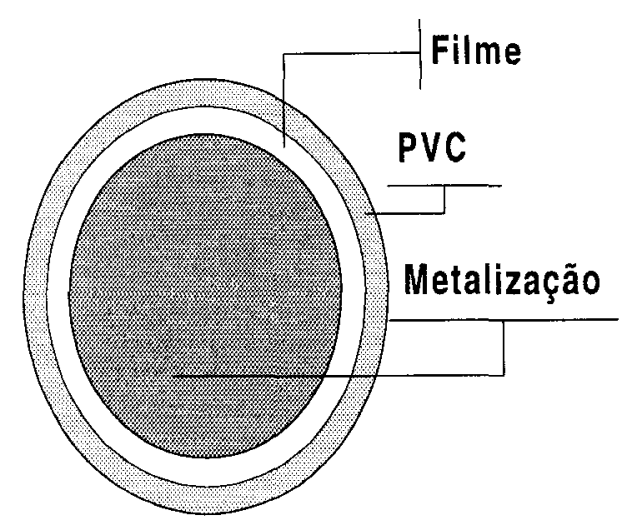

FIGURA 14 - Representação de uma amostra no anel de PVC.

\subsection{2 - Filmes de PMMA}

Os filmes de PMMA com o corante DR1 foram preparados a partir da solução do polímero (hospedeiro) com o corante (hóspede). O polímero e o solvente são misturados sob agitação até que o polímero esteja totalmente dissolvido e em seguida acrescenta-se o corante. Para preparação das soluções corante-PMMA e corante-PS utiliza-se o clorofórmio. Filtra-se a solução (polímero-cromóforosolvente) para a eliminar as impurezas e eventuais partes de polímero ou corante não dissolvidos. Para obter os filmes usa-se a técnica de espalhamento da solução polímero e corante. Nesta técnica, a solução é espalhada sobre uma placa de vidro através de um extensor. A espessura do filme é, em média, $12 \mu \mathrm{m}$. Por se tratar de um material quebradiço não foi possível fixa-lo em bastidor. As amostras não foram metalizadas e para fazer o contato elétrico nas medidas do coeficiente piroelétrico utilizaram-se borrachas semicondutoras. 


\section{6 - Técnicas de polarização das amostras}

\subsection{1 - Rampa de tensão}

As amostras de PVDF foram polarizadas utilizando método de rampa de tensão (Sawyer-Tower modificado) [26], onde a amostra é colocada em circuito fechado com os eletrodos e submetidas a ciclos de tensão. Na montagem utilizada pode-se controlar todo o processo através de computador. A Figura 15 ilustra a montagem experimental do circuito de rampa de tensão. O sistema usado neste trabalho consiste de um gerador de rampa, um amplificador de alta tensão (fonte TREK), um eletrômetro para medir a corrente elétrica, a amostra, a placa conversora $\mathrm{A} / \mathrm{D}$ e $\mathrm{D} / \mathrm{A}$ e o microcomputador.

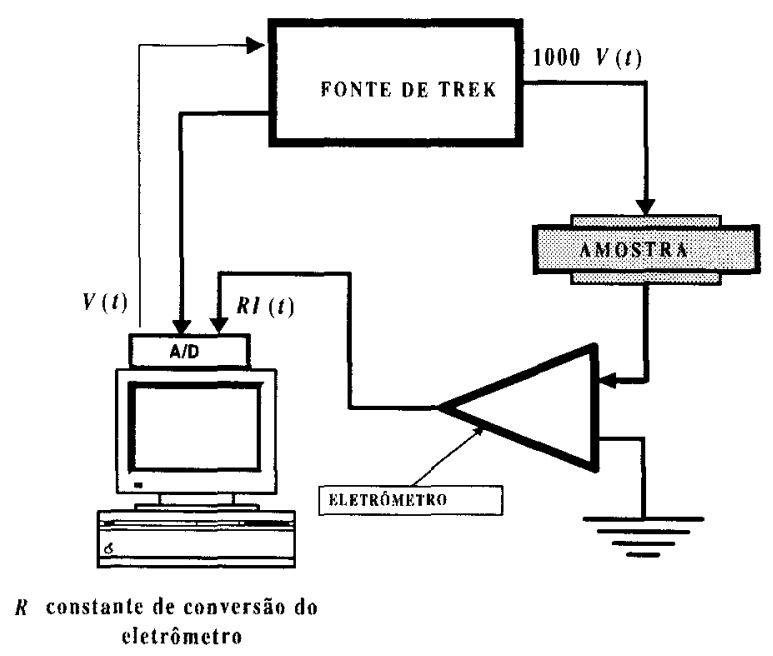

Figura 15 - Diagrama esquemático do circuito de rampa de tensão.

O processo de polarização das amostras de PVDF foi realizado à temperatura ambiente, aplicando-se rampa de tensão com taxa de subida de $38 \mathrm{~V} / \mathrm{s}$ até a amplitude máxima desejada. Em geral, aplicou-se pelo menos duas vezes a rampa de tensão (com mesma polaridade). 


\subsection{2 - Triodo de corona}

O efeito corona [27] é uma descarga auto-sustentável não disruptiva a qual ocorre quando uma diferença de potencial suficientemente alta é aplicada entre dois eletrodos assimétricos, tal como uma ponta e um plano. No processo de polarização de filmes por corona [27], uma das superfícies da amostra está sujeita aos íons da descarga corona. $\mathrm{O}$ aumento da carga elétrica na superfície do filme proporciona um aumento do campo elétrico no volume da amostra para alinhar os dipolos. É conhecido que uma grade metálica, inserida entre a ponta corona e o dielétrico, fornece um modo simples de controle do fluxo de íons para a superfície da amostra, configuração denominada de triodo corona. Recentemente a montagem foi aperfeiçoada por GIACOMETTI [28, 29] permitindo depositar cargas na superfície da amostra a uma taxa constante. Esta técnica, denominada de triodo de corona com Corrente Constante tem sido utilizada para polarizar filmes ferroelétricos e para óptica não linear. Uma revisão sobre descarga corona, suas utilizações e a descrição do triodo de corona com corrente constante pode ser encontrada na referência [27].

A Figura 16, ilustra o diagrama esquemático do triodo de corona com corrente constante. O sistema experimental consiste basicamente de uma ponta metálica $(\boldsymbol{E})$ para a geração de íons por corona, uma grade metálica $(\boldsymbol{G})$ de controle e um suporte para as amostras. A fonte de alta tensão $\left(\boldsymbol{V}_{\boldsymbol{c}}\right)$ é usada para gerar a descarga corona e o eletrômetro ( $\boldsymbol{E}$ ) é usado para medir a corrente da amostra. A fonte $V_{g}$ é realimentada com o sinal do eletrômetro para manter a corrente de carregamento constante.

No método de corrente constante a medida do potencial da amostra é feita a partir da tensão de grade, $\mathbf{V}_{\mathbf{g}}$, e seu registro permite determinar o potencial durante a deposição dos íons na amostra. 


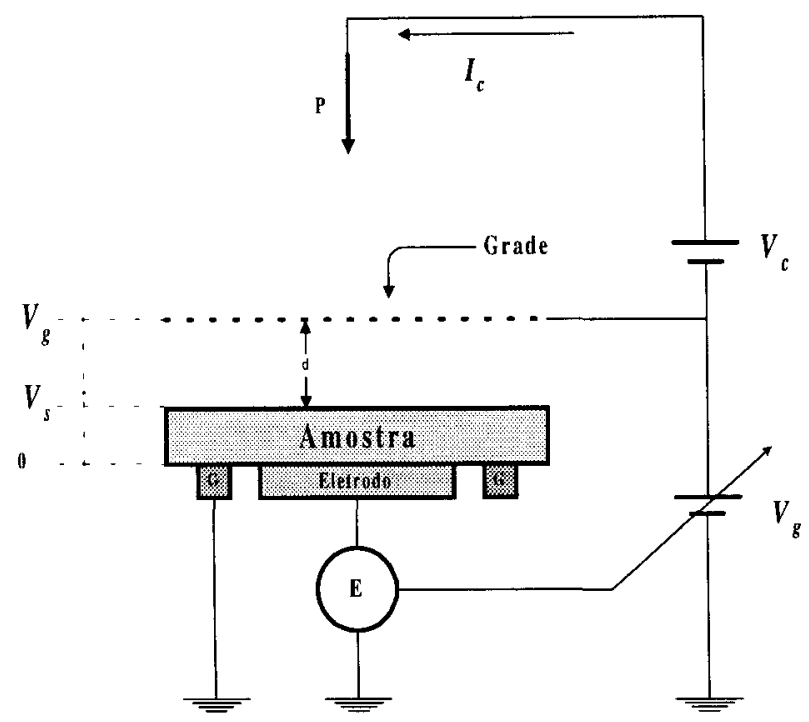

FigURA 16 - Diagrama esquemático do triodo corona com corrente constante. $P$ é a ponta corona, $\boldsymbol{G}$ é o anel de guarda, $\boldsymbol{E}$ é o eletrômetro que mede a corrente, $\boldsymbol{V}_{\boldsymbol{c}}$ é a fonte de alta tensão que produz a descarga corona em $\boldsymbol{P}$ e, $\boldsymbol{V}_{\boldsymbol{g}}$ é a fonte de tensão (operando no modo corrente constante) que polariza a grade.

Freqüentemente citam-se vantagens da polarização por descarga corona, tais como: (a) Pode-se realizar carregamento de filmes não metalizados ou apenas na face em contato com o eletrodo inferior; (b) pode-se polarizá-los sob altos campos elétricos (mesmo com rupturas localizadas); (c) a técnica é muito conveniente para filmes grandes e (d) consegue-se alta uniformidade no processo de deposição de cargas. 


\section{CAPÍTULO IV}

\section{RESULTADOS}

\section{1 - Introdução}

Neste capítulo descreve-se as características e intervalo de operação do sistema experimental e os resultados experimentais de medidas da atividade piroelétrica em materiais poliméricos. As amostras utilizadas foram de PVDF na fase $\beta$ biaxialmente estiradas e PMMA dopado com DR1(PMMA+DR1). As técnicas experimentais utilizadas para polarizar as amostras e induzir a atividade piroelétrica foram a rampa de tensão em circuito fechado e o triodo corona mostrados nos itens 3.6.1 e 3.6.2.

No item 4.2 é mostrado o procedimento para determinar o coeficiente piroelétrico, as características e os limites de operação do sistema. Para essa caracterização utilizou-se uma amostra de PVDF previamente polarizada com campo elétrico da ordem de $300 \mathrm{MV} / \mathrm{m}$. No item 4.3 e 4.4 mostram-se os resultados do coeficiente piroelétrico para o PVDF e do PMMA+DR1 em função dos parâmetros de polarização elétrica dos filmes, por exemplo, temperatura e campo elétrico máximo aplicado. 


\section{2 - Desempenho do sistema}

Os parâmetros que podem ser variados nas medidas do coeficiente piroelétrico são a freqüência e a amplitude da variação da temperatura. Devido à inércia térmica dos eletrodos é necessário utilizar variações de temperatura de baixa freqüência, i.e., da ordem de $\mathrm{mHz}$. Como já foi mencionado a água circula no interior do porta amostra a temperatura constante, determinando a temperatura da amostra (o controle é feito através do banho termostático, Polystat ${ }^{\circledR}$ ) e garante a temperatura de referência para as células. A variação desta se somaria à variação senoidal da temperatura, interferindo nas medidas. De fato, durante as medidas observou-se que a falta de cuidado com a isolação térmica do sistema, a temperatura da água que circula no interior do porta amostra pode variar devido a mudança da temperatura ambiente.

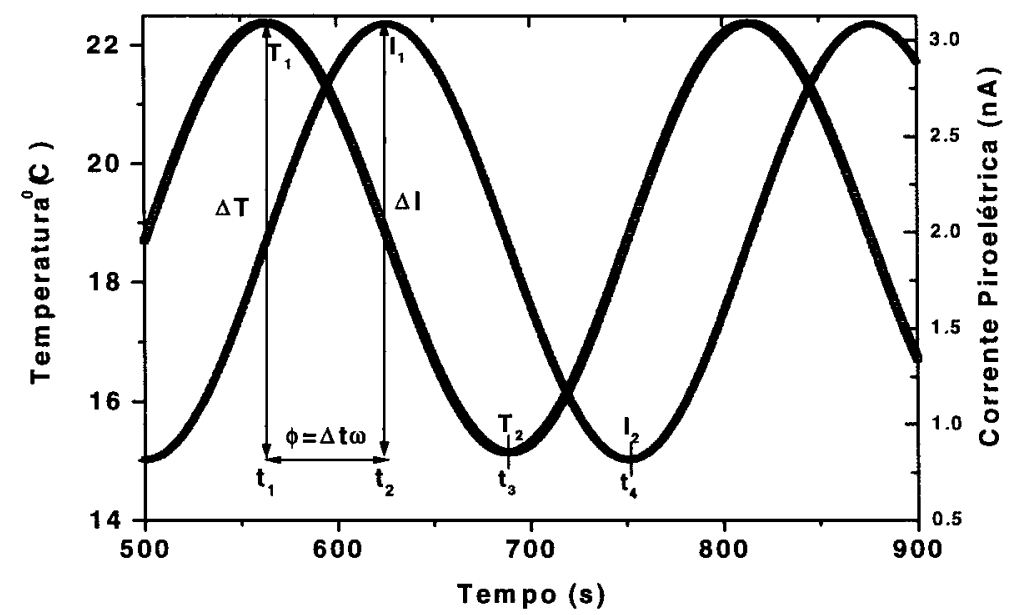

FiguRA 17 - Temperatura e corrente versus tempo para a temperatura média de $18,90 \mathrm{C}$ e freqüência de $4 \mathrm{mHz}$. Amostra de PVDF $12 \mu \mathrm{m}$.

Descreve-se a seguir o procedimento para a determinação do coeficiente piroelétrico.

A Figura 17 mostra um exemplo das curvas da temperatura e corrente em função do tempo, para frequiência $\mathrm{f}=4 \mathrm{mHz}$. $\mathrm{O}$ programa do computador, usado para o controle 
e aquisição de dados experimentais (temperatura e corrente elétrica), mostra na tela do computador as curvas de temperatura e corrente permitindo a visualização dos resultados. Durante a medida os dados são automaticamente transferidos pelo programa de aquisição para a planilha de dados do programa gráfico ORIGIN. O cálculo do coeficiente piroelétrico é feito a partir das curvas mostradas no programa ORIGIN (Método 1). Os valores de temperatura, corrente elétrica e tempo são medidos diretamente na tela do computador usando as ferramentas "coordenadas de tela" do programa ORIGIN. A partir destes dados, veja exemplo na Tabela 1, determina-se a amplitude de temperatura, $\Delta \mathrm{T}$, a amplitude de corrente, $\Delta \mathrm{I}$, e a diferença de tempo, $\Delta \mathrm{t}_{\mathrm{m}}$, entre as cristas dos sinais $\left(\Delta \mathrm{t}_{\mathrm{m}}\right.$ também pode ser determinado pela parte inferior das curvas). A temperatura média da amostra, $T_{m}, e m$ torno da qual ocorre a variação senoidal, é determinada tomando-se o valor médio da amplitude máxima e mínima da temperatura. A diferença de fase angular, $\phi_{\mathrm{m}}$, é determinada por $\phi_{m}=2 \pi f \Delta t_{m}$, e então o coeficiente piroelétrico é calculado a partir da equação (II.12).

TABELA 1 - Valores de $\Delta \mathrm{tm}, \Delta \mathrm{T}, \Delta \mathrm{I}, \mathrm{Tm}$, e $\phi_{\mathrm{m}}$ para as curvas da Figura 17

\begin{tabular}{|l|l|l|l|l|}
\hline$\Delta \mathrm{t}_{\mathrm{m}}(\mathrm{s})$ & $\Delta \mathrm{T}\left({ }^{0} \mathrm{C}\right)$ & $\Delta \mathrm{I}(\mathrm{nA})$ & $\mathrm{T}_{\mathrm{m}}\left({ }^{0} \mathrm{C}\right)$ & $\phi_{\mathrm{m}}$ (graus) \\
\hline 62 & 6,9 & 2,3 & 18,9 & 89,2 \\
\hline
\end{tabular}

Um procedimento alternativo (método 2) é ajustar as curvas de temperatura e corrente em função do tempo com funções do tipo senoidal e a partir dos parâmetros ajustados calcula-se o coeficiente piroelétrico. Este método é mais trabalhoso que o anterior, razão pela qual durante o trabalho se optou pelo o primeiro método, mas saliente-se que os resultados obtidos são praticamente iguais. Para 
referência, a Tabela 2 mostra os valores obtidos pelo dois métodos para diferentes frequiências, a temperatura média de $48,2^{\circ} \mathrm{C}$. Outro resultado interessante dessas medidas é a diferença de fase entre a corrente e a temperatura é muito próxima de 90 ${ }^{\circ}$, veja Tabela 2. No caso de amostras de PVDF observou-se a independência do angulo de fase com a amplitude, Figura 19 e a freqüência de oscilação da temperatura e também com a temperatura da amostra. Este resultado facilita a determinação do coeficiente piroelétrico do PVDF, pois não é necessário realizar a medida da fase para todas as medidas.

Tabela 2 - Valores experimentais obtidos pelos dois Métodos de cálculo (M1método 1 e M2-método 2). Temperatura média $48,2^{\circ} \mathrm{C}$.

\begin{tabular}{|l|l|l|l|l|l|l|l|l|l|l|l|}
\hline \multirow{2}{*}{$\mathrm{f}(\mathrm{mHz})$} & \multicolumn{2}{|l|}{$\Delta \mathrm{t}_{\mathrm{m}}(\mathrm{s})$} & \multicolumn{2}{l|}{$\left.\Delta \mathrm{T}_{\mathrm{m}}{ }^{0} \mathrm{C}\right)$} & \multicolumn{2}{l|}{$\Delta \mathrm{I}(\mathrm{nA})$} & \multicolumn{2}{l|}{$\phi(\mathrm{Graus})$} & \multicolumn{2}{l|}{$\mathrm{p}\left(\mu \mathrm{C} /{ }^{0} \mathrm{Cm}^{2}\right)$} \\
\cline { 2 - 11 } & $\mathrm{M}_{1}$ & $\mathrm{M}_{2}$ & $\mathrm{M}_{1}$ & $\mathrm{M}_{2}$ & $\mathrm{M}_{1}$ & $\mathrm{M}_{2}$ & $\mathrm{M}_{1}$ & $\mathrm{M}_{2}$ & $\mathrm{M}_{1}$ & $\mathrm{M}_{2}$ \\
\hline 2 & 123,0 & 125 & 8,3 & 8,4 & 1,7 & 1,8 & 88,0 & 89,9 & 30,7 & 30,4 \\
\hline 3 & 83,0 & 83,3 & 7,8 & 7,9 & 2,5 & 2,5 & 89,9 & 89,9 & 30,2 & 30,2 \\
\hline 4 & 60,5 & 62,5 & 7,2 & 7,3 & 3,0 & 3,1 & 86,0 & 89,9 & 29,4 & 29,9 \\
\hline
\end{tabular}

Como foi mencionado no item 2.3.3 o coeficiente piroelétrico de uma amostra pode ter valores positivos e negativos. No caso do PVDF o coeficiente é negativo pois, com o aumento da temperatura a polarização elétrica diminui. Para identificar o sinal da corrente elétrica adota-se a convenção da Figura 18. A cargas induzidas mostradas na Figura 18, são devidas as polarizaç̃̃es elétricas (orientada para a direita da figura) e no caso do PVDF o aumento da temperatura diminui a polarização como mostrado na Figura 18 gerando uma corrente negativa através do eletrômetro. Este comportamento é mostrado nas curvas de corrente e temperatura 
mostradas na Figura 17, i.e., a corrente elétrica está atrasada em relação a temperatura.

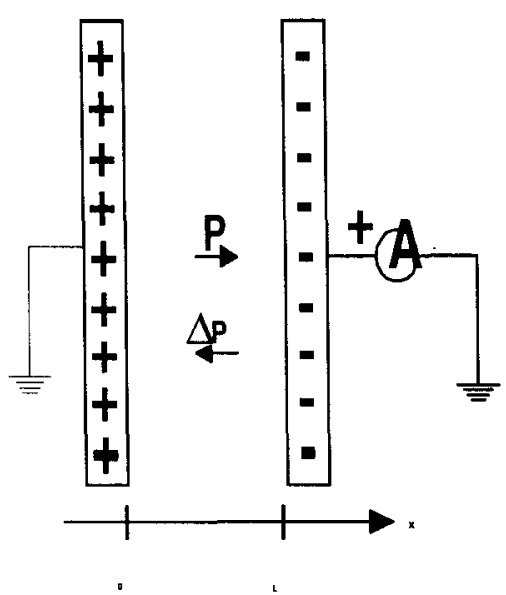

FiguRA 18 - Diagrama para a convenção do sinal do coeficiente piroelétrico A é eletrômetro x é a coordenada, $\mathrm{P} \mathrm{e} \Delta \mathrm{P}$ são a polarização e sua variação.

O intervalo de frequiência de operação do sistema é limitado por vários fatores experimentais. Quanto maior a frequiência de medida, mais rápida será a sua realização, fato este muito desejável. O limite inferior é determinado pela sensibilidade da medida da corrente elétrica, pois quanto menor a freqüência menor será a corrente elétrica gerada pela amostra, veja equação II.8. No caso do PVDF a atividade piroelétrica é muito intensa que permitiria fazer medidas até frequiências da ordem de microhertz. O limite superior é limitado pela difusividade térmica da amostra e pela inércia térmica do sistema. O limite determinado pela propagação do calor numa amostra de $12 \mu \mathrm{m}$ de espessura permitiria realizar medidas até freqüências da ordem de centenas de hertz [6]. Por outro lado à inércia térmica do conjunto e o contato térmico entre a amostra e as células de Peltier dificultam o aumento da freqüência. No sistema construído pode-se operar o sistema sem grandes problemas até a frequência de $10 \mathrm{mHz}$, veja Figura 19, e para freqüências maiores seria necessário introduzir correções nas medidas. Detalhes dessas correções não serão discutidos aqui. 


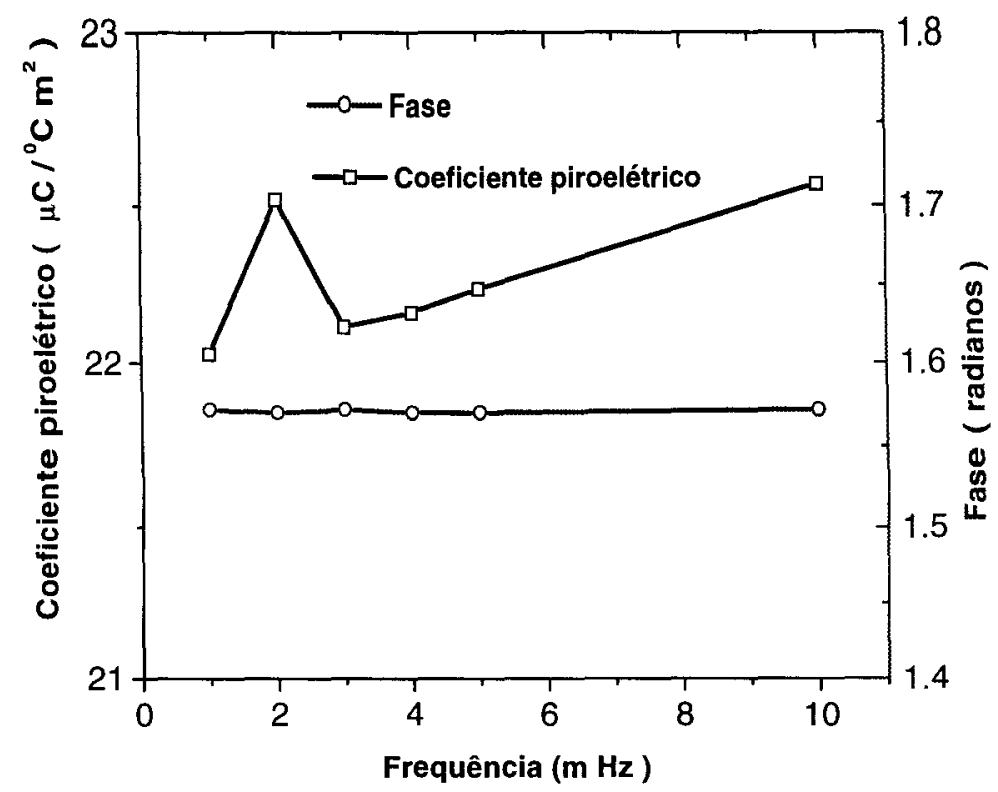

Figura 19 - Coeficiente Piroelétrico versus freqüência de oscilação da temperatura para um campo de polarização de $250 \mathrm{MV} / \mathrm{m}$.

Outro fator que pode afetar a medida do coeficiente piroelétrico é a amplitude de oscilação da temperatura. Os testes realizados, (ver Figura 20) mostraram que mesmo que a amplitude de oscilação atinja $10{ }^{\circ} \mathrm{C}$, em torno da temperatura média da amostra, não se observou desvios significativos nos resultados da determinação do coeficiente piroelétrico. 


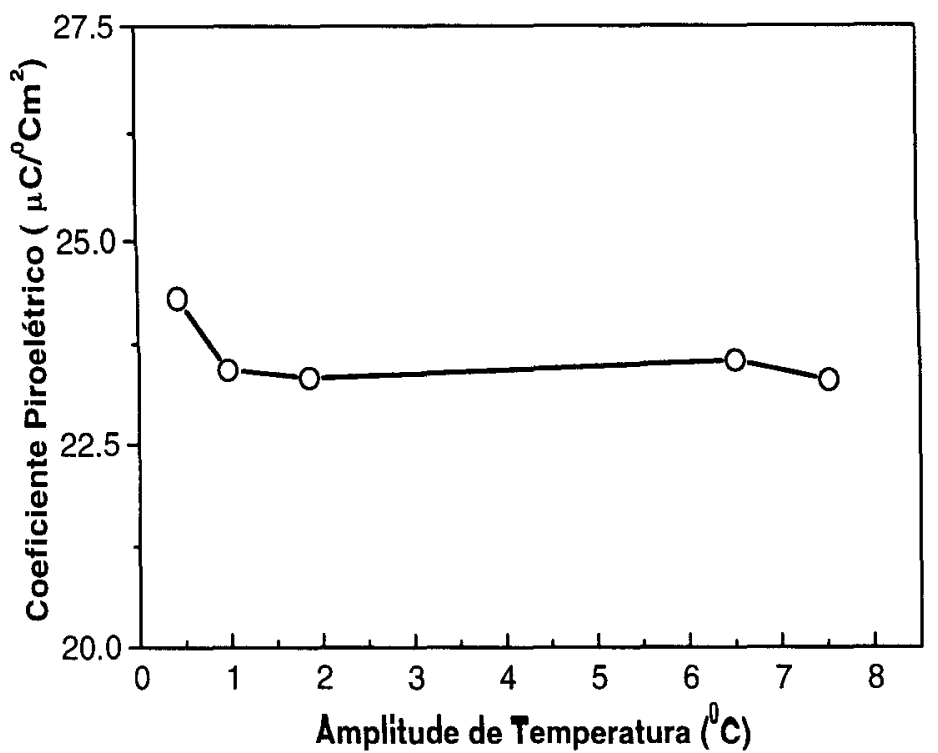

Figura 20 - Coeficiente Piroelétrico versus Amplitude de Temperatura com campo de polarização de $250 \mathrm{MV} / \mathrm{m}$.

Como comentário final saliente-se que a montagem implementada permite realizar medidas com uma boa confiança no intervalo de 1 a $10 \mathrm{mHz}$ e amplitudes de oscilação temperatura de até $10{ }^{\circ} \mathrm{C}$. A sensibilidade do método depende da amplitude e frequêencia de oscilação da temperatura, veja figura 21 , que mostra o crescimento da amplitude da corrente com a freqüência. A sensibilidade da medida dependente da medida da corrente piroelétrica, i.e., da sensibilidade do eletrômetro. No caso do PVDF vê-se da Figura 21, que a amplitude da corrente medida é da ordem de nanoampères, ou seja, tem-se condições de medir coeficiente piroelétrico da ordem de até alguns $\mathrm{nC}^{\circ} \mathrm{Cm}^{2}$ pois o eletrômetro mede, sem muita dificuldade, correntes elétricas da ordem de $\mathrm{pA}$. 


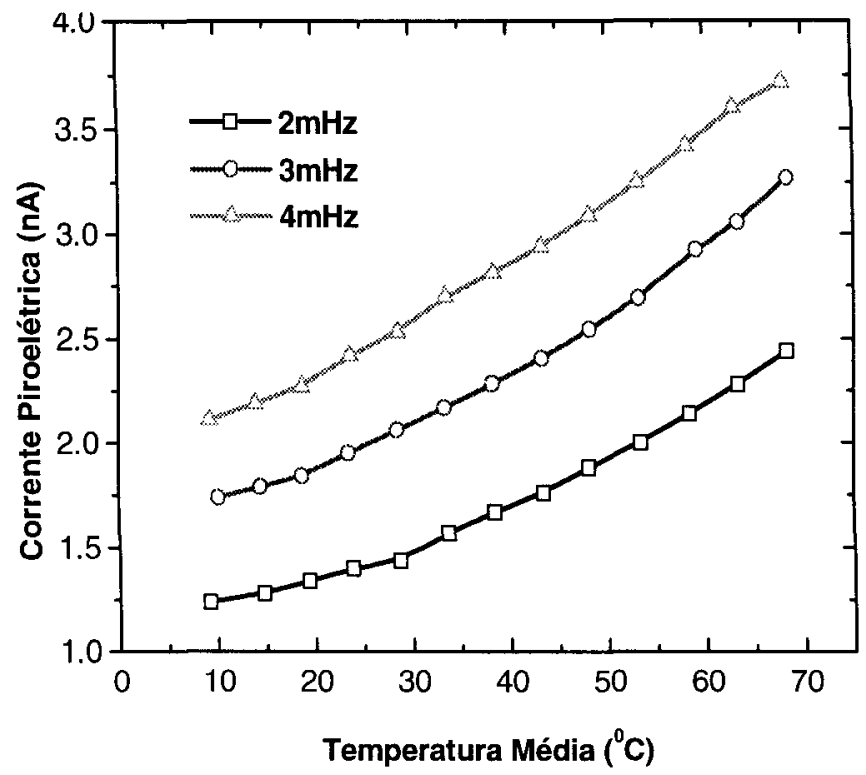

FIGURA 21 - Medidas da corrente piroelétrica versus a temperatura para frequiências de $2 ; 3$ e $4 \mathrm{mHz}$.

\section{3 - Resultados com o PVDF}

Os resultados apresentados a seguir têm como objetivo mostrar as medidas do coeficiente piroelétrico do PVDF. As medidas foram feitas em função das condições de polarização da amostra, temperatura e do tempo. Para polarizar e induzir a atividade piroelétrica nas amostras de PVDF foi empregado o método de rampa de tensão já descrito no item 3.6.1. No método pode-se variar a tensão máxima, a taxa de subida da rampa, a temperatura ambiente durante o processo de polarização.

Os procedimentos empregados nas medidas para o PVDF foram:

$1^{\circ}$ - Inicialmente as amostras são polarizadas até um campo elétrico máximo, a temperatura ambiente, aplicando vários vezes a rampa de tensão.

$2^{\circ}$ - remove-se a amostra colocando-a no sistema para medida do coeficiente piroelétrico. 
$3^{\circ}$ - as medidas em função da temperatura da amostra foram realizadas aumentandose ou diminuindo a temperatura de 5 em 5 graus.

\subsection{1 - Coeficiente piroelétrico versus temperatura média.}

As curvas da Figura 22, mostram o coeficiente piroelétrico (mostrado em valor absoluto) em função da temperatura no intervalo de 10 a $70^{\circ} \mathrm{C}$, dois dias após a amostra ter sido polarizada com tensão máxima de $3 \mathrm{KV}$. Observa-se que o coeficiente piroelétrico aumenta com a temperatura média de forma não linear. Notase que a temperatura ambiente o coeficiente piroelétrico é de ordem de $22 \mu \mathrm{C} /{ }^{0} \mathrm{Cm}^{2}$, o qual concorda com publicações anteriores $[11,19,23,24,30]$.

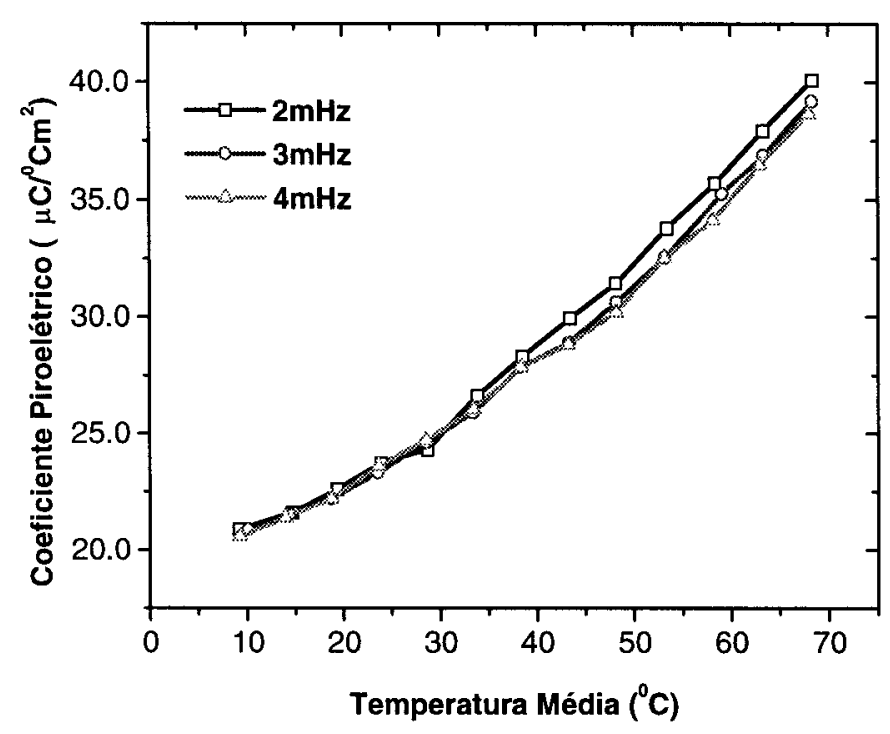

Frgura 22 - Coeficiente Piroelétrico versus Temperatura, Frequiências entre 2; 3 e $4 \mathrm{mHz}$.

O gráfico da Figura 23, mostra o coeficiente piroelétrico, também em função da temperatura para a amostra de PVDF após o processo de polarização. A curva A representa a medida do coeficiente piroelétrico realizada dois dias após a amostra ser polarizada e a curva $\mathbf{B}$ após 26 dias. Observa-se uma diminuição no valor do coeficiente piroelétrico. Esta figura ilustra que uma parte da atividade piroelétrica 
desaparece $[11,30]$ mas medidas deste decaimento não serão investigadas neste trabalho.

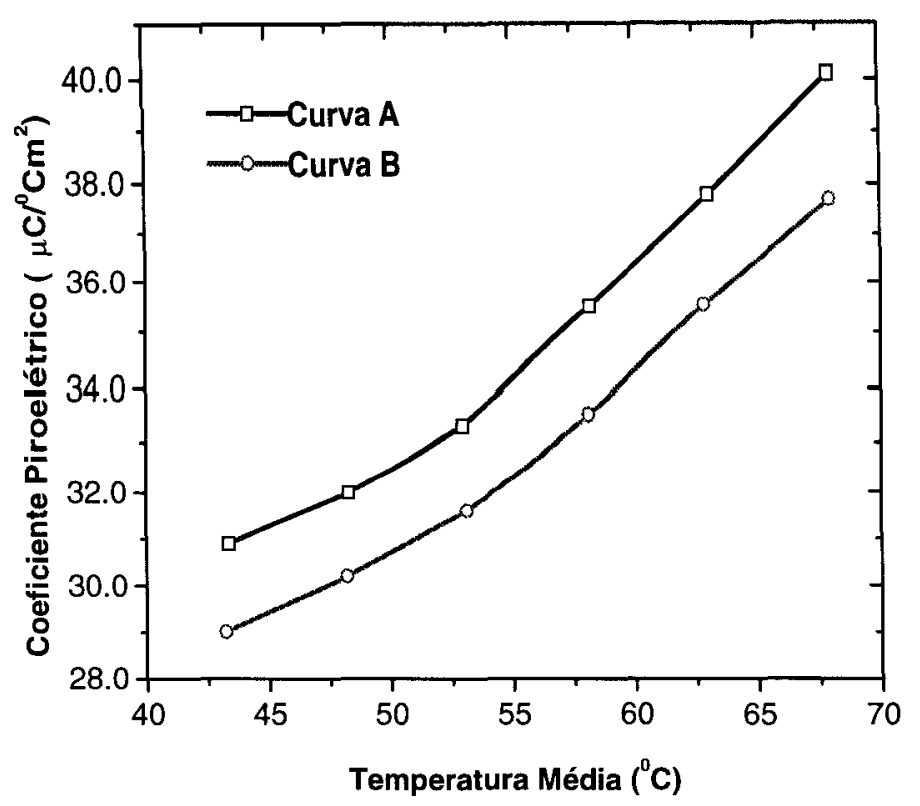

FiguRA 23 - Coeficiente piroelétrico após 2 e 26 dias após o processo de polarização com campo de $250 \mathrm{MV} / \mathrm{m}$ aplicado na amostra. Frequiência de $4 \mathrm{mHz}$.

\subsection{2 - Coeficiente piroelétrico versus campo elétrico de polarização}

Foi medida a dependência coeficiente piroelétrico com o campo de polarização, para uma amostra virgem de PVDF (como recebida do fabricante e com polarização ferroelétrica nula) submetendo-se a amostra à campos elétricos crescentes, de 0 a $250 \mathrm{MV} / \mathrm{m}$, em intervalos de $41.6 \mathrm{MV} / \mathrm{m}$ (500 volts). Para cada processo de polarização a amostra foi cinco vezes submetida a rampa de tensão com 1000 s de duração. Após a polarização a amostra foi mantida em curto circuito durante 12 horas e então o coeficiente piroelétrico foi medido à temperatura ambiente. A Figura 24, mostra a dependência do coeficiente piroelétrico com o campo elétrico de polarização. Para campos pequenos (menores que $50 \mathrm{MV} / \mathrm{m}$ ) observa-se que o coeficiente piroelétrico é praticamente zero e tende a um valor de saturação para campos acima de $250 \mathrm{MV} / \mathrm{m}$. O ponto de inflexão da curva, que 
corresponde à variação máxima da polarização com o campo, é associado com o campo coercivo do material, apresenta valores maiores que os encontrados na literatura. Nota-se que o coeficiente piroelétrico máximo nesta medida é da ordem $17,6 \mu \mathrm{C} / \mathrm{Cm}^{2}$ e menor que os valores típicos encontrado na literatura. $\mathrm{O}$ valor menor é devido ao pequeno valor da polarização elétrica induzida na amostra pois ela ainda possui uma parte cristalina na fase $\alpha$. Este fato é confirmado pois amostras polarizadas com campo elétrico de maior valor, da ordem de $300 \mathrm{MV} / \mathrm{m}$, com muitos ciclos de rampa de tensão (acima de 20) apresentam o coeficiente piroelétrico da ordem de $22 \mu \mathrm{C} / \mathrm{Cm}^{2}$.

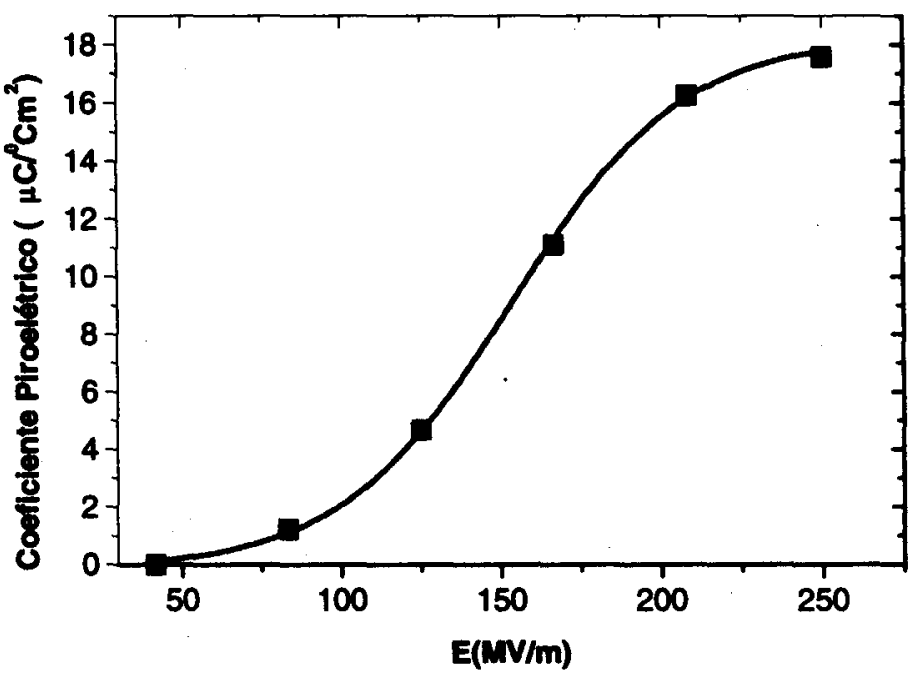

Figura 24 - Coeficiente Piroelétrico versus campo elétrico, $f=10 \mathrm{mHz}$.

\subsection{3 - Comparação do coeficiente piroelétrico com a polarização elétrica}

É interessante comparar os resultados mostrados na Figura 25, dependência do coeficiente piroelétrico com o campo, com a curva de polarização elétrica ḿ̧fida em função do campo elétrico determinada durante a aplicação da rampa dé tensão. Nesta medida utilizou-se uma amostra já orientada e os valores do 
coeficiente piroelétricos foram determinados utilizando-se o mesmo procedimento descrito anteriormente. A amostra foi submetida a campos crescentes de 0 a $250 \mathrm{MV} / \mathrm{m}$, com variação de $21 \mathrm{MV} / \mathrm{m}$ (250 volts), durante 2 ciclos com período proporcional a tensão aplicada. Após cada processo de polarização, a amostra foi colocada em curto circuito durante 1 hora e logo após o coeficiente piroelétrico foi medido à temperatura ambiente. A curva da polarização versus campo elétrico foi determinada a partir da corrente elétrica medida durante a aplicação da rampa de tensão. A partir da corrente determinou-se a polarização seguindo o procedimento descrito na literatura [30]. A curva em linha continua na Figura 25, mostra a polarização elétrica medida em função do campo elétrico enquanto que os pontos representam o coeficiente piroelétrico. Observa-se que o coeficiente piroelétrico possui um comportamento praticamente igual ao da polarização o que é esperado, pois o coeficiente piroelétrico é diretamente proporcional a polarização elétrica da amostra. Para campos pequenos observa-se que o coeficiente piroelétrico é negativo e a medida que o campo aumenta ele troca de sinal e tende a saturação para campos acima de $250 \mathrm{MV} / \mathrm{m}$. A curva de polarização começa no valor nulo e atinge o valor de saturação da ordem de $120 \mathrm{mC} / \mathrm{m}^{2}$ e como a amostra tinha sua polarização orientada este valor corresponde ao dobro da polarização remanescente pois a polarização foi reorientada de 180 graus. Conhecendo o valor da polarização elétrica e o coeficiente piroelétrico para cada valor de campo pode-se determinar o valor do coeficiente de variação da polarização, $\alpha_{p}$. O seu valor é definido por

$$
\alpha_{p}=\frac{1}{P_{0}} \frac{d P_{0}}{d T}
$$

e usando a definição do coeficiente piroelétrico. Eq. II.1, tem-se que 


$$
\alpha_{p}=\frac{p}{P_{0}}
$$

Usando o resultado da Figura 25 , i.é, $\mathrm{p}=15 \mu \mathrm{C} /{ }^{0} \mathrm{Cm}^{2}$ e $\mathrm{P}_{0}=60 \mathrm{mC} / \mathrm{m}^{2}$ encontra-se 0 valor $\alpha=2,5 \times 10^{-4}{ }^{\circ} \mathrm{C}^{-1}$, que é da ordem dos valores encontrados na literatura para o PVDF e seus copolímeros (de 1 a $\left.8 \times 10^{-4}{ }^{0} \mathrm{C}^{-1}\right)[17,18]$.

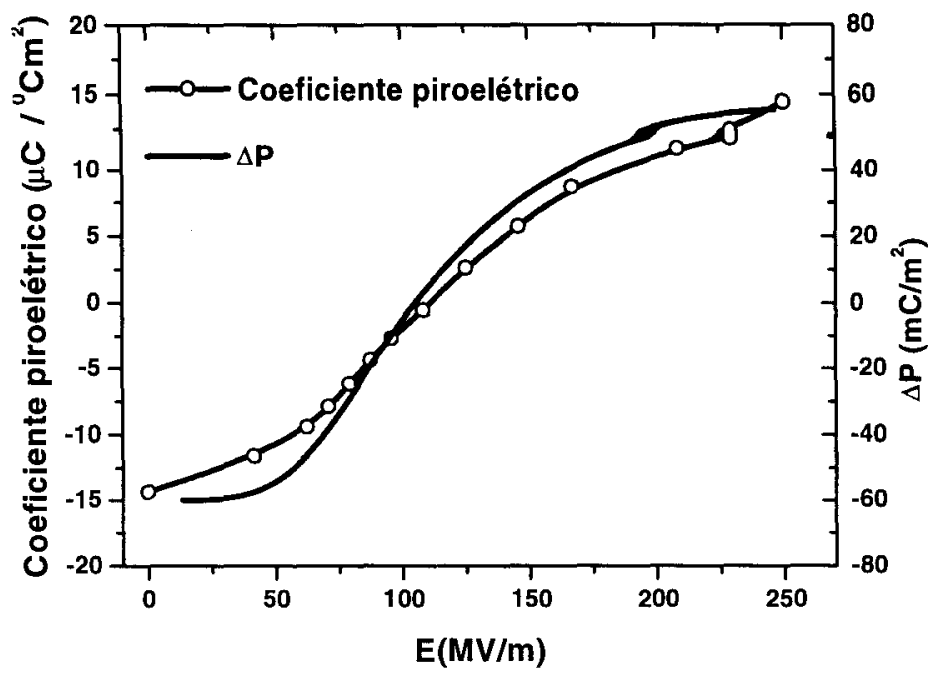

FIgURA 25 - Curva da polarização elétrica versus campo (linha cheia) e coeficiente piroelétrico versus campo de polarização. As escalas foram ajustadas para comparação das curvas.

\section{4 - Resultados com o PMMA}

Os resultados apresentados a seguir têm por objetivo mostrar as medidas do coeficiente piroelétrico no PMMA com corante DR1. As medidas foram feitas em função do campo de polarização da amostra e concentração do corante. Para polarizar e induzir a atividade piroelétrica nas amostras de PMMA foi empregado o método de triodo corona com corrente constante já descrito no item 3.6.2.

O interesse nestas medidas é o estudo da otimização do processo de polarização elétrica dos polímeros para óptica não linear [31]. Uma vez que o 
coeficiente piroelétrico é diretamente proporcional a polarização elétrica da amostra pode-se, portanto, ter uma medida indireta da polarização.

Os critérios empregados nas medidas para do PMMA com corante DR1 foram as seguintes:

$1^{\circ}$ - Inicialmente as amostras são aquecidas até $80{ }^{\circ} \mathrm{C}$ e em seguida polarizadas no triodo de corona com corrente constante até atingir o campo de polarização, aqui usamos campo de $80 \mathrm{MV} / \mathrm{m}$. A seguir o sistema é colocada no modo tensão de grade constante e deixa-se a amostra sob efeito deste campo durante o tempo em que se deseja polarizar a amostra. Depois se resfria a amostra à temperatura ambiente ainda sob carregamento de corona. Após o resfriamento neutraliza-se o potencial de superfície usando uma corrente de corona com polaridade oposta a que amostra foi polarizada.

$2^{\circ}$ - A amostra é colocada entre duas borrachas semicondutoras e colocada entre os eletrodos do sistema de medidas. As medidas foram realizadas com frequiência de $5 \mathrm{mHz}$ a temperatura ambiente.

\subsection{1 - Coeficiente piroelétrico em função do campo elétrico}

As medidas do coeficiente piroelétrico para amostras de PMMA $+6 \%$ DR1 foram realizadas a temperatura ambiente $\mathrm{e}$ as amostras polarizadas a temperatura de $80^{\circ} \mathrm{C}$, durante 30 minutos em função do campo elétrico de polarização. A Figura 26, mostra que o coeficiente piroelétrico cresce linearmente com o campo elétrico. Esta dependência é esperada uma vez que o tempo de polarização é relativamente longo e acredita-se que à temperatura de $80^{\circ} \mathrm{C}$ ele é suficiente para se atingir o valor de equilíbrio da polarização e, portanto, proporcional ao campo elétrico aplicado. 


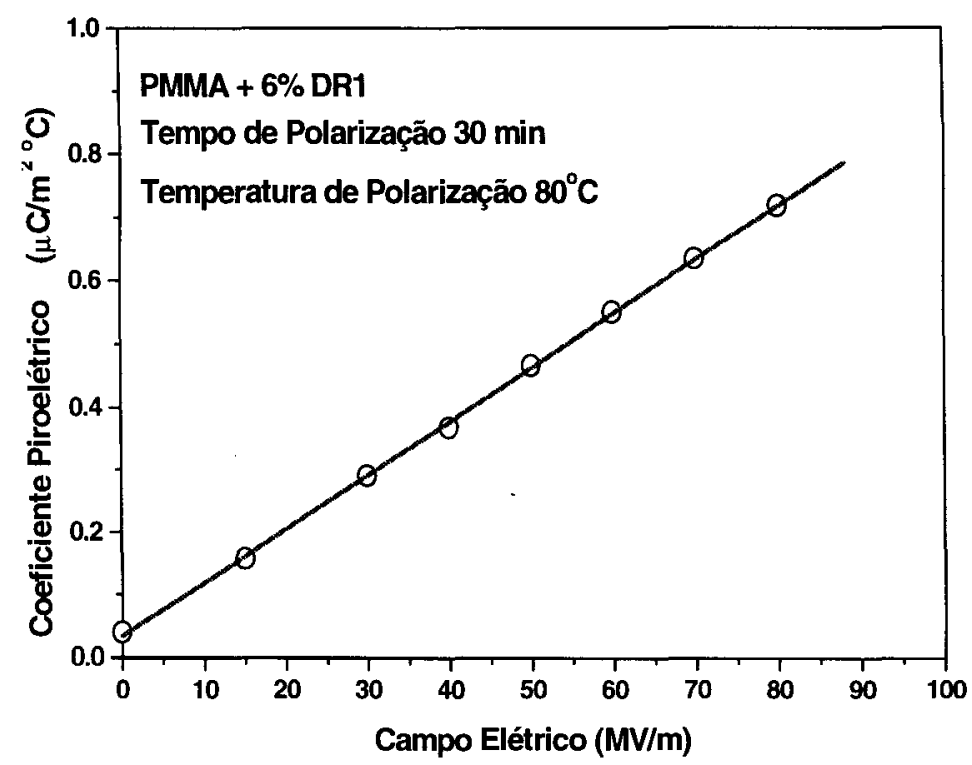

FIGURA 26 - Dependência do coeficiente piroelétrico com o campo elétrico máximo.

\subsection{2 - Coeficiente piroelétrico em função da concentração de corante}

A Figura 27 mostra a dependência do coeficiente piroelétrico com a concentração de corante. Essas medidas foram realizadas polarizando as amostras com o campo elétrico de $80 \mathrm{MV} / \mathrm{m}$, a temperatura em $80^{\circ} \mathrm{C}$ e durante o tempo de 30 minutos. Nota-se na figura que aumentando a quantidade de corante na amostra o coeficiente piroelétrico aumenta de forma linear. Este resultado mostra que o valor da polarização elétrica na amostra esta diretamente relacionado com a concentração de corante na amostra. 


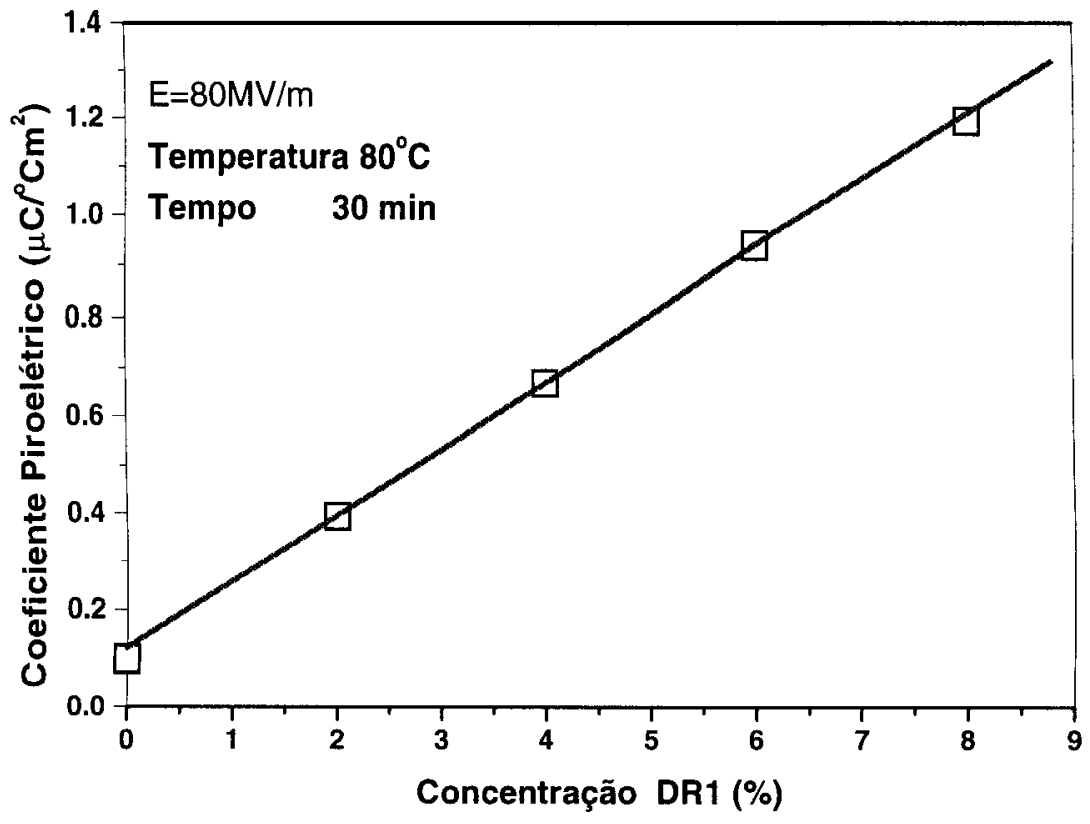

FIgURA 27 - Dependência do coeficiente piroelétrico com a concentração de DR1. 


\section{CAṔ́tulo V}

\section{COMENTÁRIOS E CONCLUSÕES}

Neste trabalho desenvolveu-se uma montagem experimental para medir o coeficiente piroelétrico de materiais poliméricos usando o método de temperatura oscilante. Na primeira parte do trabalho mostrou-se a caracterização do sistema experimental construído e determinaram-se as condições e limites de sua operação. A experiência obtida com o uso do sistema mostrou que a principal limitação, a frequiência máxima da oscilação da temperatura, é relacionada com o contato térmico entre a amostra e as células de Peltier e não com os circuitos de controle do sistema. O programa de coleta de dados foi uma ferramenta fundamental para o bom desempenho do sistema, pois através dele pode-se calcular o coeficiente piroelétrico de forma quase que totalmente automatizada. Os resultados de caracterização do sistema mostraram que ele opera de forma muito satisfatória e apenas nos faltou uma amostra padrão para se ter uma aferição mais precisa da técnica. $O$ sistema construído de tal forma que permite com pequenas modificações, variar-se a temperatura de diferentes formas para se determinar o coeficiente piroelétrico de outras maneiras e para realizar outros tipos de caracterização de materiais poliméricos

Neste trabalho o método foi empregado para iniciar a caracterização de dois materiais poliméricos: o PVDF e PMMA dopado com corante polar. Os resultados parciais mostrados nesta dissertação foram bastante animadores abrindo

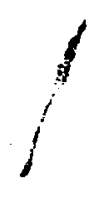


grande perspectiva para trabalhos futuros. O método mostrou ser adequado para avaliar a polarização elétrica no PMMA com corante (o coeficiente piroelétrico é diretamente proporcional à polarização) o que permite estudar a eficiência do processo de polarização elétrica das amostras em função dos parâmetros de carregamento por descarga corona. No caso do estudo de materiais como o PVDF o método permite a avaliação das características das propriedades ferroelétricas de filmes, ou seja, pode ser usado como um método independente de avaliação da polarização elétrica.

Fica registrado aqui como sugestão para trabalhos futuros a comparação dos resultados obtidos aqui com os obtidos com métodos de variação não senoidal da temperatura e o uso do método para estudar outros materiais tais como as cerâmicas ferroelétricas. 


\section{REFERÊNCIAS BILIOGRÁFICAS}

[1] Kawai, H. Piezoelectricity of Poly(Vinylidene Fluoride). J. Appl. Phys. 8, 975 (1969).

[2] Bergman,J.G.; McFee, J. U.; and Craner, G. R.,'Pyroelectricity and Optical Second Harmonic Geration in Polyvinylidene Fluoride “, Appl.Phys.Lett.,18, 203 (1971)

[3] Nakamura, K.; Wada, Y, "Piezoelectricity and the Electrostriction Constant of Poly (vinilidene fluoride), J.Polym. Sci., 9, 163 (1971)

[4] Kepler, R.G., and Anderson, R. A.,"Ferroelectric polymers". Adv.Phys., $41,1(1992)$

[5] Xiao, D. Q, and Lang, S.B.,"Measurement applications based on pyroelectric properties of ferroelectric polymers"',IEEE Trans. Electr. Insul., $23,50(1989)$

[6] Dias, C., Simon, R., Quad, R., and Das-Gupta, D. K., "Measurement of the pyroelectric Coefficient in Composites Using a Temperature Modulated Excitaction, J. Appl. Phys.,26,106 (1993)

[7] Harthey, N. P., Squere,P. T. and Putley,E. H.,'A new method of measuring pyroelectric coefficients", J.Physics E: Sci. Inst., 5,789 (1972)

[8] Garn, L. E. and Sharp, E. J. ,Üse of low-frequency sinusoidal temperature waves to separate pyroelectric currents from nonpyroelectric currents". Part Iand II,J.appl. Phys., 53, 8974-8987 (1984)

[9] Lovinger, 'J.,"Development in Crystaline Polymers-1", D.C. Basset Ed., ApllieSci. Publisher, Gordon (1982)

[10] Hilczer, B.and Malechy, J., "Studies in electral and electronic Egineering 14"electrets, ed.Elsevier, p343-366 (1986)

[11] Kepler, R.G.,and Anderson, R. A., "On The Origin of Pyroelectricity in Polyvinylidene fluoride", J. Appl. Phys., 49,4918(1978)

[12] Burkard, H. and Pfister, G.,"Reversible pyroelectricity and inverse Piezoelectricity in Polyvinylidene Fluoride",J. Appl. Phys.,45,3360(1974)

[13] Das-Gupta, D. K.and Duffy, J. S,"Pyroelectricity in Polyvinylidene Fluoride", J.Appl. Phys.,50,561(1979)

[14] Bauer, S. and Lang, S.,"Pyroelectric Polimer Electrets", IEEE Transactions on Dielectrics and Electral Insulution.,3,647 (1996) 
[15] Davis, G. T., Mckinney, Broadhurst, M. G. and Roth,Sc.,"Electric -Field inducePhase change in Poly(vinylidene Fluoride)",J.Appl.Phys., 49,4948,(1978)

[16] Putley, E. H.,'The Applications of Pyroelectric Devices", Ferroelectrics, 33,207(1981)

[17] Das-Gupta, D. K.,'Pyroelectricity in Polimers", Ferroelectrics, 118, 165 (1991)

[18] Furukawa, T.,"Piezoelectriccity and Pyroelectricity in Polymers", IEEE Transactions on Electral Insulation., 24,375(1989)

[19] Teyssèdre, G.,Bernés,A. and Lacabanne, C.,'Temperatura Dependence of The Pyroelectric Coefficient in Polyvinylidene Fluoride", Ferroelectrics, 160, 67 (1994)

[20] Broadhurst, M. G. and Davis, "Topics in Appl., Electrets",Ed. G.M.Sessler, Springer -Verlag, Berlin ,285(1980)

[21] Purvis, C. K., and Taylor P.L,'Piezoelectricity and Pyroelectricity in Polyvinylidene Fluoride: Influênce of The Lattice Struture,,J. Appl. Phys., $54,1021,(1983)$

[22] Frederick, I.M. and Broadhurst, G.M.,"Molecular Dipole Electrets",J. Appl.Phys.,46,4204, (1975)

[23] Broadhurst, M. G., Davis, G. T. and Mckinney, J. E., "Piezoelectricity and Pyroelectricity in Polyvinylidene Fluoride - A Model", J. Appl. Phys.,49,4992, (1978)

[24] Wada, Y. and Hayakawa, R.,"A Model Theory of Piezo- and Pyroelectricity of Poly(vinylidene Fluoride) Electret", Ferroelectrics, 32, 115 (1981)

[25] Ohigashi,H.,"Electromechanical properties of polarized polyvinylidene fluoride films by the piezoelectric resonance method"., J. Appl. Phys.,47,949, (1976)

[26] Moura, W. A., "Determinação da Polarização Ferroelétrica do PVDF Estirado Biaxialmente Utilizando A técnica de corrente Constante"., São Carlos, 1998. Dissertação de Mestrado-Instituto de Física de São Carlos, Universidade de São Paulo.

[27] Giacometti, J. A., Oliveira Jr, O.N, "Corona Charging of Polymer". IEEETrans.Elec.Ins.,5, 924, (1992)

[28] Giacometti, J. A.,Campos, J. S. C. "Constant Current Corona Triode with grid Voltage Control.Application to Polymer Foil charging".,Ver.Sci.Instrument., $61,1143(1990)$ 
[29] Campos, J. S.Carvalho."Novo Triodo e sua Aplicação no Estudo das Propriedades Elétricas do Polímero PVDF. São Carlos,1990. Tese de Doutoramento-Instituto de Física de São Carlos, Universidade de São Paulo.

[30] Wada, Y.,and Hayakawa, R. "Piezoelectricity and Pyroelectricity of Polymers”.;Jnp.J.Appl.Phys., 15, 2041 (1976)

[31] Costa, M. M.,. Tese de Doutorado (a ser defendida)-Instituto de Física de São Carlos, Universidade de São Paulo - São Carlos, 1999. 